NBER WORKING PAPER SERIES

\title{
INVESTMENT RETURNS AND DISTRIBUTION POLICIES OF NON-PROFIT ENDOWMENT FUNDS
}

\author{
Sandeep Dahiya \\ David Yermack \\ Working Paper 25323 \\ http://www.nber.org/papers/w25323 \\ NATIONAL BUREAU OF ECONOMIC RESEARCH \\ 1050 Massachusetts Avenue \\ Cambridge, MA 02138 \\ December 2018, Revised April 2021
}

For helpful comments we thank Turan Bali, Jeff Busse, Kent Daniel, Edwin Elton, Wayne Ferson, Mark Flannery, Martin Gruber, Ludovic Phalippou, Jay Ritter, Michael Ryngaert, Jialan Wang (conference discussant), Quan Wen, and seminar participants at the 2019 American Finance Association annual meeting, the 2019 Q-Group conference, American University, Deakin University, University of Delaware, Erasmus University Rotterdam, University of Florida, Georgetown University, New York University, and the University of Western Australia. Research assistance by Rainier Go and Pranav Marupudi is greatly appreciated. The views expressed herein are those of the authors and do not necessarily reflect the views of the National Bureau of Economic Research.

NBER working papers are circulated for discussion and comment purposes. They have not been peer-reviewed or been subject to the review by the NBER Board of Directors that accompanies official NBER publications.

(C) 2018 by Sandeep Dahiya and David Yermack. All rights reserved. Short sections of text, not to exceed two paragraphs, may be quoted without explicit permission provided that full credit, including $(\odot$ notice, is given to the source. 
Investment Returns and Distribution Policies of Non-Profit Endowment Funds

Sandeep Dahiya and David Yermack

NBER Working Paper No. 25323

December 2018, Revised April 2021

JEL No. G11,G35,L31

\begin{abstract}
$\underline{\text { ABSTRACT }}$
We present the first estimates of investment returns and distribution rates for U.S. non-profit endowments, based on a comprehensive sample of 35,755 organizations for 2009-2018, a period that saw a sharp drop followed by a lengthy appreciation in public equity values. Non-profit endowments badly underperform market benchmarks during our sample period. Holding a zero investment portfolio (long endowment and short 60-40 mix of U.S. equity and Treasury bond indexes) generates a mean $-4.20 \%$ annual return. Regression estimates in four-factor models including U.S. stocks and bonds, global stocks, and hedge funds, find statistically significant alphas of $-0.39 \%$ per year. Smaller endowments have less negative alphas than larger endowments, but all size classes significantly underperform. Distribution ratios are conservative, well below the funds' long-run returns. Donors increase contributions when endowment returns are strong, with an elasticity of about 0.20 between net-of-market investment returns and new donations.
\end{abstract}

Sandeep Dahiya

McDonough School of Business

Georgetown University

Washington, DC 20057

Sandeep.Dahiya@georgetown.edu

David Yermack

Stern School of Business

New York University

44 West Fourth Street, Suite 9-160

New York, NY 10012

and NBER

dyermack@stern.nyu.edu 


\section{Investment Returns and Distribution Policies of Non-Profit Endowment Funds}

\section{Introduction}

Endowment funds are repositories for gifts and operating surpluses generated by nonprofit organizations. Often described by their parent organizations as "nest eggs" or "rainy day funds," endowments invest in stocks, bonds, and alternative asset classes such as hedge funds and private equity, and they pay income to their parents to subsidize operating costs and capital expenditures. In recent decades, many endowments have grown rapidly due to an influx of gifts as well as riskier investment policies that have increased their returns. Probably the best-known example is Yale University, which in 2020 reported having grown to \$31.2 billion with an annualized return of $9.9 \%$ per year over the prior 20 years. ${ }^{1}$ The exponential growth of Yale’s and other high-profile universities' endowments has led to scrutiny of the objective functions of their parent organizations ${ }^{2}$ and, as of 2018, a new $1.4 \%$ federal income tax on the net investment income of certain wealthy universities.

Yet little is known about the overall size, performance, and use of endowments in the non-profit sector. The small number of papers on endowment returns have typically focused

\footnotetext{
${ }^{1}$ https://news.yale.edu/2020/09/24/investment-return-68-brings-yale-endowment-value-312-billion. The same source indicated that annual endowment distributions currently represent 35\% of Yale's net revenue, indicating the vital role its endowment plays in supporting the university's operating and capital budgets.

2 “There is an old joke that describes Harvard as a \$37 billion hedge fund with a university attached.” Barry Ritholtz, “The Day Harvard Stopped Being a Hedge Fund,” Bloomberg View, January 26, 2017.
} 
only on funds that support major colleges and universities. These studies all rely on self-reported information from voluntary samples that take no account of selection bias or survivorship bias. The best known study, Lerner, Schoar and Wang (2008), uses annual data from the National Association of College and University Business Officers (NACUBO). The NACUBO source is also used by Brown, Garlappi and Tiu (2007), Barber and Wang (2013), and several other papers, and while it continues to publish annual surveys, the size of NACUBO's voluntary opt-in sample peaked in 2010 at 850 institutions and fell to 705 by 2020. Cejnek, Franz, Randl and Stoughton (2014) provide a literature review of the academic and trade research into the university endowment sector, which seems to have crowded all other non-profit endowment research to the sidelines until now.

This paper presents a comprehensive survey of endowment returns and distribution policies for the period 2009-2018 in all U.S. non-profit sectors. We test the hypothesis that endowments earn returns equal to widely used market benchmarks, using data provided by nonprofit organizations in annual Form 990 filings with the Internal Revenue Service (IRS). Our extraction of data from these filings yields a sample of 265,548 annual endowment observations reported by 35,755 organizations in all non-profit sectors. A recent working paper by Lo, Matveyev, and Zeume (2020) uses the same IRS data source that we do and appears to have a similar sample. This newly available dataset is much larger and broader than those used in earlier endowment research focused on higher education.

Overall the funds in our study earn negative abnormal investment returns. The median annual investment return for endowments is $2.57 \%$ between 2009-2018. Weighting our observations by the time periods in which they occur, the benchmark returns on ten-year Treasury bonds are 3.39\% per year and the equity market index returns $12.13 \%$ per year over the 
same measurement periods. The median endowment fund under-performs a 60-40 combination of the equity and Treasury bond market indexes by about 3.92 percentage points annually, and the mean difference is almost the same at -4.20 percentage points. On a risk-adjusted basis, we use a four factor model that includes three exchange traded funds (ETFs) that capture performance of U.S. equities, non-U.S. equities, fixed income and hedge fund returns to estimate alphas of $-0.39 \%$ for our entire sample, statistically significantly below the $1 \%$ level, with the most negative alpha estimates applying to the largest size cohorts.

Figure 1 shows that the underperformance of market benchmarks by endowment funds has been consistent and often substantial. The figure shows the mean annual returns for endowment funds during individual, non-overlapping fiscal year reporting periods minus a benchmark 60/40 portfolio of equity and debt market indexes during each period (details on the sample and calculation of returns appear below). The left-most bar shows annual performance for endowments with fiscal years ending in January 2009, the second bar covers annual performance for funds with fiscal years ending in February 2009, and so on until our sample concludes with the $120^{\text {th }}$ bar representing annual performance for endowments with fiscal years ending in December 2018. In the top half of Figure 1, data are shown for an equal-weighted average of endowment funds, and these fall short of the basic market benchmark in 107 of the 120 reporting periods. In the bottom half, data for a size-weighted average of endowment funds underperform the benchmark in 85 out of 120 reporting periods.

These poor investment results largely agree with those realized by other investor classes, which typically exhibit zero or negative alpha estimates in standard performance attribution regression models. See, e.g., the well known research into mutual funds by Fama and French (2010), individual investors by Barber and Odean (2000), hedge funds by Brown, Goetzmann, 
and Ibbotson (1999), and private equity by Franzoni, Nowak, and Phalippou (2012), among many other performance measurement studies.

We study the distribution policies of non-profit endowments to their parent organizations, which resemble the shareholder dividend policies that are an important research topic in corporate finance. We find that most endowments have conservative distribution policies that imply payouts below their long-run expected returns, and well below the actual returns realized during the sample period for our study. These cautious distribution policies would tend to cause endowments to grow without limit over time. The smallest endowment funds make no payouts at all in most years, implying that organizations seek to grow them to a critical mass before tapping them as permanent funding sources. For the largest endowments, those with asset values above \$100 million, distributions occur almost every year, with mean and median distribution rates near $4.5 \%$, which appears to have become a heuristic that enjoys wide acceptance in the non-profit sector without much theoretical justification.

The remainder of this paper is organized as follows. Section II presents a description of the data. Section III analyzes endowment funds’ investment returns, and Section IV analyzes their distribution policies. Section V studies whether donations to parent organizations respond positively to good investment returns in endowments. Section VI concludes the paper.

\section{Data description}

Our data come from Form 990, a document filed annually with the IRS by most nonprofit operating organizations in the U.S. ${ }^{3}$ Since 2008, Part V of Schedule D for Form 990 has

\footnotetext{
${ }^{3}$ Form 990 must be filed by non-profits with gross receipts over $\$ 200,000$ or total assets over $\$ 500,000$. Smaller organizations may file Form 990-EZ, which excludes the endowment data used in this study. In practice these smaller organizations are unlikely to maintain endowments.
} 
required those organizations with endowment funds to provide annual data including the fund balance at the beginning of the year, contributions, distributions, administrative expenses, and net investment earnings. These data are a matter of public record, but obtaining them for a large sample of organizations has been impractical up to now, because online databases of information from Form 990 filings such as Guidestar have all omitted coverage of this schedule.

We use Form 990 data that has been posted by the IRS since 2016 on Amazon Web Services (AWS) as a result of a lawsuit filed by Carl Malamud, an advocate for transparency in the nonprofit sector. ${ }^{4}$ The website hosts annual schema of all electronic Form 990 filings beginning in 2011. The electronic filing requirements have been phased in gradually since 2006, and we believe our sample, especially in the most recent years, covers substantially all of the private endowment assets in the United States for operating charities. However, a major exception occurs for churches and religious organizations, which generally do not file financial disclosure forms with government regulators due to the constitutional principle of separation of church and state. ${ }^{5}$ Our sample will also exclude certain endowment funds connected to public universities, which may be managed by state governments that do not file with the IRS, and it

\footnotetext{
${ }^{4}$ The data are downloadable by the public from https://registry.opendata.aws/irs990/, although we found that considerable effort is required to parse the files, extract the relevant variables, and clean the data before it is suitable for large-sample research. A description of Malamud's successful federal lawsuit to compel the IRS to disclose the data in this way can be found at https://sunlightfoundation.com/2016/06/16/irs-opens-up-form-990-data-usheringnonprofit-sector-into-the-age-of-transparency/.

${ }^{5}$ Major denominations' financial wealth has been the subject of speculation for centuries. In the U.S., a whistleblower complaint filed with the IRS in 2019 indicated that the Church of Latter Day Saints had amassed an investment fund of approximately $\$ 100$ billion, much larger than any endowment in our sample and about double the size of the largest private foundation, the Gates Foundation. However, the massive value of the LDS fund is likely unique. The Roman Catholic Archdiocese of New York, surely one of the wealthiest religious non-profits in the U.S., publishes excerpts from audited financial reports each year on its website at https://archny.org/financialreports. For the most recent period ended August 31, 2018, the Archdiocese reported cash and investments of \$336 million, a total including not only endowment assets but also working capital. This sum is orders of magnitude below the fund balances held by major research universities, though the most significant wealth of the U.S. Catholic church may be held in real estate and fine art rather than financial investments. Catholic endowment assets may also be decentralized to individual parishes for risk management and governance reasons and not consolidated into the balance sheets of central administrative entities such as archdioceses, of which the U.S. has 32. Various entities of the U.S. based Church of Scientology appear to hold assets of approximately $\$ 2$ billion, according to press reports.
} 
will also exclude endowments of private grant-making foundations such as the Ford Foundation or Gates Foundation, because non-operating foundations report separately to the IRS on Form 990-PF.

We create our sample by downloading all available data on the AWS website, which had grown to more than 1.9 million organization-year observations by January 2021. As described more completely in Appendix 1, we first remove duplicate observations and then add additional observations based on the availability of up to four years of lagged historical data in the IRS's endowment table. We then drop more than 1.7 million observations for years in which organizations do not report having endowments, leaving a candidate sample of 243,341 observations. To organize our dataset in calendar time, we assign each filing to the year that includes the final month of its chosen fiscal year. ${ }^{6}$

Starting with our candidate sample, we apply a series of data screens to identify problem observations with incomplete or inconsistent data. In some cases, we are able to cure the problems by looking ahead to future years' filings, since four years of lagged historical data are typically available and some organizations will correct prior years’ errors. We lose 6,377 observations for which the beginning or ending endowment asset values are reported as missing or zero. Some of these cases may represent years in which new endowments are launched or complete liquidations occur. In 134 cases organizations file Form 990 for an irregular fiscal year reporting period of less than 360 or more than 370 days, and we drop these observations. We eliminate 8,437 observations that represent two or more organizations sharing the same endowment fund and simultaneously reporting it on Form 990, to avoid double-counting the

\footnotetext{
${ }^{6}$ Unlike for-profit companies that tend to have fiscal years coinciding with the calendar and ending in December, the most common fiscal year-end for non-profits is June 30 , which is used by $41 \%$ of all observations in the sample. An additional 40\% have December fiscal years, and the other 19\% are scattered among the remaining ten calendar months.
} 
same endowment two or more times in the sample. We increase the sample by backfilling 61,366 observations reported as lagged historical data in the first electronic filings by each organization. At this point we have a sample size of 289,759.

We next check all observations for internal consistency against the equation for an identity that is implicit in the IRS's filing format: end-of-year endowment assets must equal starting assets, plus contributions, less grants and other distributions, plus investment gains, less administrative expenses and other expenses. For $96 \%$ of the observations this identity holds exactly (in a minority of cases we must adjust for sign conventions by taking the absolute value of outflows in order to make the identity hold). We resolve some discrepancies in the 11,537 (or 4\%) of observations that lack internal consistency by looking ahead to future years’ filings, which sometimes correct prior years’ errors. This allows us to hold onto 2,475 corrected observations. We also retain 5,011 observations for which the identity is satisfied to a tolerance of 1\%, and we end up excluding 4,051 observations that lack acceptable internal consistency and cannot be repaired.

We elect to restrict the sample to observations beginning no earlier than 2009 and ending no later than 2018, since data are quite incomplete either before or after this data range. This results in the deletion of 4,707 older observations and 14,899 filings for 2019 and 2020.

Finally, we trim from the sample the top and bottom $0.1 \%$ of observations for annual investment return, as calculated by our method described below, reducing our sample size by a total of 532. These outlier observations appear to represent reporting errors, such as the misclassification of endowment withdrawals as “expenses” that lead to the calculation of a very 
negative investment return. We conclude the sample construction with a sample size of 265,548. Please see Appendix 1 for additional detail about our sample. ${ }^{7}$

Table 1 shows that the sample sizes gradually increase up to 2015 and then level off at about 29,000 endowments per year. The growth in annual observations likely occurs due to the gradual adoption of electronic filing by organizations during the sample period. In all, we have data for 35,755 unique filing organizations, and the annual sample size peaks at 29,469 in 2015. We expect that a number of late filings will eventually occur for years subsequent to 2015 so that the sample sizes will eventually increase to approximately the same size that we have in 2015.

Our analysis focuses on the rates of return earned by endowment funds. As reported to the IRS, investment returns are based on dividends, interest, and capital appreciation of the market values of funds' assets rather than only their realized gains. An organization can either include its expenses as part of a report of net investment earnings on Line 1c of this schedule, or it can report gross investment earnings on Line 1c while listing administrative expenses separately on Line 1f. For the minority of organizations that follow the latter practice, we calculate net investment earnings by subtracting any value reported on Line $1 \mathrm{f}$ from Line 1c. We then calculate the annual investment return by taking the ratio of net investment earnings over the sum of start-of-year assets plus one-half of contributions minus one-half of distributions. Contributions generally include bequests, gifts, and other funds deposited into endowments, while distributions consist of grants, scholarships, and transfers to the organization's operating accounts. Thus, our calculation implicitly assumes that the typical contribution is received

\footnotetext{
${ }^{7}$ Lo, Matveyev, and Zeume (2020) report a sample size of 191,525 fund-year observations, much smaller than ours, but have about the same number of individual funds, 34,777 vs. the 35,755 funds in our sample. That paper gives almost no detail about the resolution of data problems such as individual endowments that are reported on the balance sheets of more than one non-profit entity, the use of leads and lags of annual endowment data when available from organizations' Form 990 tables, or the elimination from the sample of endowments with missing or inconsistent data, so we are unable to come to a conclusion about why our sample includes so many more fund-year observations compared to the sample in the other paper.
} 
halfway through the fiscal year and that any distributions from the fund also occur halfway through the year. We test the importance of these timing assumptions in sensitivity analysis reported below, and we find that they have no material effect on our results.

Due to these limitations of the available data, our calculations of investment performance lack the precision of measures such as the time-weighted returns commonly used to evaluate professional asset managers. A further limitation to our analysis arises from the absence of information about asset allocation, which is not a mandatory disclosure on the IRS Form 990, although for some organizations it can be obtained through a careful reading of certain schedules and appendices (these tend to present the data in narrative form, so that downloading a large sample is impractical). Lo, Matveyev, and Zeume (2020) use these narrative disclosures to obtain asset allocation data for 41,512 out of the 191,525 observations in their sample, or $21.6 \%$, and the tabulation of this data represents a major contribution of that paper. However, since the large majority of observations have missing values, and the reporting of asset allocation data may be affected importantly by selection effects and obfuscation strategies, we do not attempt to collect and analyze this information in our study. ${ }^{8}$

Table 1 presents further detail about the distribution of endowment assets by year and by industry sector. We follow the 12 major industry classification (ntmaj12) scheme of National Taxonomy of Exempt Entities (NTEE). Aggregate U.S. endowment assets surpassed \$776 billion as of 2018, and nearly two-thirds of this total is held by colleges and universities in the Higher Education sector and additional organizations in the "Education (Other)" sector that

\footnotetext{
${ }^{8}$ As an example of obfuscation, Yale University’s 2017 Form 990 filed on September 20, 2018 reports a balance of \$27.4 billion in its endowment fund (Schedule D, Part V) and on the next page indicates that \$24.7 billion is held in “equity investments” (Schedule D, Part VII). This data obviously cannot be taken at face value, and it is hard to tell how information of this type might have been handled in the tabulations of Lo, Matveyev and Zeume (2020). Yale's separately released annual endowment report for 2017 provides far more clarity, indicating asset allocation of 25\% to hedge funds, $17 \%$ to venture capital, $15 \%$ to foreign equity, $14 \%$ to leveraged buyouts, $11 \%$ to real estate, $8 \%$ to natural resources, $5 \%$ to U.S. bonds, $4 \%$ to U.S equity, and $1 \%$ to cash (see https://investments.yale.edu/reports).
} 
includes research bureaus and private secondary schools. Organizations with their main operations in the arts, hospitals, other healthcare sectors, social services, and other "public and social benefit” areas account for most of the rest of the endowment funds. As shown in the table, several hundred religious organizations also file disclosures even though many could avail themselves of reporting exemptions.

Table 2 presents descriptive statistics for the sample. The table shows endowment data for the sample of 265,589 observations alongside basic financial data for 159,840 fiscal years of their parent organizations. We have significantly more observations for annual endowment performance due to the availability of up to four years of historical performance data for endowment funds on Schedule D, Part V, as noted above. The typical endowment size, as measured at the beginning of each fiscal year, is quite small, with a mean of \$23.1 million and median of $\$ 0.9$ million, but the largest funds run into the tens of billions, with a maximum value of $\$ 36.4$ billion (Harvard University, 2016). ${ }^{9}$ Outside the education sector, the largest funds are the MasterCard Foundation (\$13.97 billion as of 2018) and the Shriners Hospitals for Children ( $\$ 7.5$ billion as of 2018). The median annual net investment return, calculated according to our method, is $2.57 \%$, and the median distribution ratio is lower, $1.73 \%$.

\section{Investment returns}

This section presents our analysis of investment returns. Subsection III.A includes basic overview statistics and comparisons with equity and debt market benchmarks. Subsection III.B

\footnotetext{
${ }^{9}$ Harvard announced publicly that its endowment was worth $\$ 37.6$ billion at that time, even as its Form 990 filing indicated a value of \$36.4 billion. We contacted financial officials at Harvard and three other major universities where we observed similar reporting discrepancies, and all of them indicated that their universities' public announcements aggregated the endowment totals of several distinct legal entities, each of which filed its own Form 990. These affiliate organizations' endowments would appear in our dataset as separate observations, but we take extensive steps to avoid double-counting the same endowment assets if listed by two or more organizations. More details appear in Appendix 1.
} 
estimates the risk-adjusted abnormal returns for endowment funds, and we analyze these results in different size cohorts. Subsection III.C investigates the returns of endowments in the higher education sector, including comparisons of our results to those for colleges and universities in the widely used NACUBO sample.

\section{A. Overview of endowment returns}

Table 3 presents summary statistics for annual endowment returns for the entire sample and four subsamples partitioned by size. We use average start-of-year assets for each fund to determine membership in the size cohorts. For comparison we show returns on the Center for Research in Securities Prices (CRSP) value-weighted equity index, the CRSP 10-Year U.S. Treasury Bond Index, and a "balanced portfolio" comprised of 60\% of the equity index and $40 \%$ of the Treasury bond index. ${ }^{10}$ All index returns are aligned with the fiscal year reporting periods for each endowment, which accounts for slight differences in the benchmark returns for the four size cohorts. Data in the table represent means, medians and inter-quartile ranges for 12-month reporting periods and should not be interpreted as compound annual returns for 2009-2018, because observations are not uniformly distributed through time. Many endowments’12-month reporting periods end in June or December, and the number of observations generally rises over time to reflect increasing compliance with IRS electronic filing requirements especially by smaller organizations.

Data in Table 3 show a fairly dismal pattern of endowment returns. The mean and median returns for the entire sample are $4.44 \%$ and $2.57 \%$, respectively, The median falls not only 607 basis points below the 60-40 balanced portfolio return, but also 82 basis points below

\footnotetext{
${ }^{10}$ The $60 \%$ - 40\% combination of the equity and bond indexes is a heuristic commonly used to evaluate the performance of asset managers. For example, Barber and Wang (2013) refer to "the 60/40 stock/bond portfolio used as a performance benchmark by many endowments.”
} 
the 10-Year Treasury bond return. Looking at the size-weighted mean return instead of the equal-weighted mean makes very little difference. Within the four size cohorts of Table 3, we find that the largest endowment funds, those with assets greater than $\$ 100$ million, exhibit the highest median returns, an outcome that runs counter to our analysis of endowments' riskadjusted abnormal returns below.

Our 2009-2018 sample period represents an atypical market environment which includes a financial market collapse that began in 2008 and continues into our first year, followed by an extremely strong recovery of the equity markets beginning in late 2009 and continuing up to the end of the sample. For most of the sample period bonds also earn strong returns, due to a Federal Reserve policy of driving interest rates to sustained record lows. In addition, the alternative investments held by many larger endowments increase sharply in value toward the end of our sample period, when an IPO wave begins, and some endowments may have been slow to re-value their illiquid positions in venture capital, private equity, and related categories. Readers may therefore interpret our results with caution if these market conditions seem so unusual that they are unlikely to hold in the steady state. Our results are not materially different than those in Lo, Matveyev, and Zeume (2020), although those authors report most of their statistics after taking the average returns for each endowment and then calculating descriptive statistics over the sample of funds as opposed to the sample of fund-years as we do. Taking averages within funds may introduce some bias, since larger organizations tend to have longer time series (stretching back to the crisis years of 2009 and 2010) due to their earlier compliance with the IRS’s electronic filing requirements.

Older NACUBO studies about the performance of higher education endowments prior to the global financial crisis have led to very different conclusions about overall endowment 
performance. We cannot validate the older research, which uses a much smaller sample and is concentrated upon one industry sector, because the government disclosures that enable us to look more broadly at endowment performance do not begin until 2009. As discussed in Section III.C below, the more recent NACUBO studies show under-performance by higher education endowments in a pattern very similar to our findings for the universe of all non-profit endowments, and whether these poor endowment results will persist remains a question for the future.

For the interested reader, Appendix 2 presents a more detailed version of Table 3, with the performance statistics reported for all observations with 12-month fiscal reporting periods ending in each of the 120 months during the 2009-2018 sample. The median endowment return is lower than the $60 / 40$ benchmark in 110 out of the 120 fiscal reporting periods.

\section{B. Risk-adjusted abnormal returns}

To estimate risk-adjusted excess returns, we use the model:

$$
\left(R_{i, t}-R_{f, t}\right)=\alpha_{i}+\beta_{i, V T I}\left(R_{V T I, t}-R_{f, t}\right)+\beta_{i, V E U}\left(R_{V E U, t}-R_{f, t}\right)+\beta_{i, A G G}\left(R_{A G G, t}-R_{f, t}\right)+\beta_{i, H F R I}\left(R_{H F R I, t}-R_{f, t}\right)+\varepsilon_{i, t}
$$

The Excess Return is estimated as $\left(R_{i, t}-R_{f, t}\right)$, where $R_{i, t}$ is the annual return for endowment $i$ for year $t$, defined as the 12-month fiscal reporting period for that non-profit organization. The four risk factors include three widely diversified ETFs which, in principle, the endowments in our sample might have invested in, and also the Hedge Fund Research Index, which we use to capture the returns on non-public alternative investment classes. In equation (1), VTI represents the Vanguard Total Stock Market Index ETF, a broad-based index of the U.S. equity markets; VEU represents the Vanguard FTSE All-World ex-US ETF, an index of global mid-cap and large-cap equities excluding those based in the U.S.; AGG represents the iShares Core U.S. 
Aggregate Bond ETF (AGG), an index that tracks the U.S. investment grade bond market, and HFRI represents the hedge fund research index. All four factors are measured over the same 12month period as each endowment's fiscal year. A model with indexes for U.S. stocks and bonds alongside global equity and alternative investments is similar to those used in prior endowment research such as Brown, Garlappi, and Tiu (2007, 2010) and Barber and Wang (2013).

We face a challenge implementing these models, because the estimations require up to five parameters, including the alpha intercept term, separately for each endowment fund, but our 2009-2018 sample period provides at most ten annual observations of performance data per fund. Our overall sample includes 265,548 annual observations for 35,755 endowments, and we subsample the 24,235 endowment funds that have at least seven annual observations. This subsample includes 220,235 endowment-years, or about $83 \%$ of the overall sample, and it probably imparts a slight positive bias to our estimates of alpha, since those nonprofits with uninterrupted patterns of filing annual reports are probably the most financially successful. ${ }^{11}$ We start by estimating the OLS models described in equation (1) using the time-series annual returns for each of the 24,235 endowments. For each endowment $i$, we save the coefficient estimates $\left(\hat{\alpha}, \hat{\beta}_{V T I}, \hat{\beta}_{V E U}, \hat{\beta}_{A G G}, \hat{\beta}_{H F R I}\right)$ as well as the time series of residuals $\left(\hat{e}_{i, t}\right)$. The cross-sectional averages of alpha across the 24,235 endowments funds are reported in Table 4.

To test the statistical significance of these alpha estimates, we employ the bootstrap methodology described by Kosowski et al. (2006), and the description in the following passages closely adheres to that source. For each non-profit endowment $i$, we draw a sample (with replacement) of the residuals of that fund estimated from equation (1) above. This yields

\footnotetext{
${ }^{11}$ Smaller endowments are also less likely to have longer time series, since filing requirements for the electronic Form 990 were phased in on the basis of the size of their parent organizations.
} 
pseudo-time series of resampled residuals $\left\{\hat{e}(b)_{i, t}\right\}$, where $b$ indexes the bootstrap iteration number. Thus, we scramble the time order of residuals for each endowment.

For the next step we create a time series of pseudo endowment returns imposing the condition of zero alpha. For example, in the four-factor model, these pseudo returns are simply:

$$
\text { ExcessReturn }_{i, t}(b)_{i, t}=\hat{\beta}_{i, V T I}\left(V T I_{t}\right)+\hat{\beta}_{i, V E U}\left(V E U_{t}\right)+\hat{\beta}_{i, A G G}\left(A G G_{t}\right)+\hat{\beta}_{i, H F R I}\left(H F R I_{t}\right)+\hat{e}(b)_{i, t}
$$

Note that the method for creating the pseudo return for endowment $i$ for year $t$ consists of a predicted return with a zero alpha plus a randomly bootstrapped error term. Thus by construction the pseudo-time series of returns has a true alpha of zero. There is, however, the additional error term that adds randomization, since the residuals may be sampled more than once and the residuals have been scrambled across time.

Once the pseudo time series of zero alpha returns (with a randomly sampled residual added) has been constructed for every endowment-year, we re-estimate the four factor model using these bootstrapped pseudo endowment returns as in equation (1). Even though the true alpha is zero, the estimate for alpha from this regression may be positive (or negative) if that bootstrap has drawn an abnormally high number of positive (or negative) residuals. We are now able to generate a cross-section of bootstrapped alphas for all 24,235 funds. We save the crosssection average of the alphas. This process is repeated for 1,000 bootstrap iterations, $(b=1, \ldots$. , 1,000). This repetition yields a distribution of 1,000 average (cross-sectional) alphas.

For the four-factor model, comparing the observed average alpha of -0.0039 in the top left cell of Table 4, to this distribution allows us to conduct non-parametric statistical inference. We find that the probability of average alpha being -0.0039 is less than $1 \%$ if the true alpha was zero. In other words, in our 1,000 bootstraps we obtain an average alpha of that magnitude in 
fewer than $1 \%$ of the cases, so we reject the null hypothesis that average alpha is zero below the 1\% significance level.

In addition to illustrating our main result, that endowment funds have mean risk-adjusted returns significantly below their benchmarks, Table 4 provides further detail for the four-factor model's estimates. The table shows the fraction of alpha estimates that are negative (63\%) in our subsample of 24,235 endowments, and it shows the cross-sectional average estimates for the four risk factors without testing their statistical significance. The estimate of 0.2469 for the U.S. equity market ETF risk factor implies that endowments typically invest slightly less than onequarter of their assets with exposure to the U.S. stock market.

We continue the analysis by examining separately each of the four size cohorts introduced in Table 3 above. Note that the larger endowments, which are estimated to have the worst risk-adjusted performance, account for a minor number of observations by number, but an overwhelming fraction of the invested capital in the non-profit sector. For instance, the "large" cohort of endowments, those worth more than $\$ 100$ million, include just $3.1 \%$ of the observations but $77.5 \%$ of the assets. In contrast, the very smallest endowments, those with asset values below $\$ 1$ million which we label as "tiny," comprise $47.8 \%$ of the observations in the sample but account for only $0.6 \%$ of the assets invested.

The table shows that even though all cohorts earn average alphas that are negative and significant below the $1 \%$ level, performance is markedly less negative for smaller endowments compared to larger ones. In addition, systematic risk decreases with endowment size, as shown by the estimates for the U.S. equity market return factor which declines from 0.35 to 0.19 across the size cohorts in the four-factor model. This is consistent with a wealth effect that leads to decreasing absolute risk aversion as the value of an endowment grows (Merton, 1993). We also 
find strong evidence that the largest funds are most heavily committed to alternative investments, as the $\beta_{\text {HFRI }}$ estimate increases monotonically from a miniscule 0.01 in the smallest size cohort to a large 0.22 in the biggest size cohort.

The inverse relation we find between endowment size and performance echoes the pattern found for mutual funds in several studies. This pattern is regarded as something of a puzzle, since larger funds should enjoy advantages in trading costs and access to research and other information. Chen et al. (2004) propose a range of explanations, including the costs of investing in illiquid securities, which are more commonly held by larger funds, and the administrative costs of team management that is often used by larger funds. Pollet and Wilson (2008) discuss the costs of diversification and fund family membership as possible explanations, but neither of these issues would seem relevant for endowments, which are typically the only funds overseen by their parent organizations. The liquidity explanation is possibly the most sensible, as some non-profit endowments are known to be over-weighted in alternative investments as well as small-cap securities donated by university alumni or other benefactors who found their own companies and contribute a slice of the equity to their favorite charities. ${ }^{12}$ The costs of hedging and eventually unwinding these block ownership positions may create a drag on the overall returns for certain funds.

One of the major conclusions of Lo, Matveyev, and Zeume (2020) is that larger endowments out-perform smaller ones. In comparing performance across size cohorts, that paper calculates net-of-market returns, sometimes with size or industry benchmarks used in place of the overall market, and it also reports Sharpe ratios calculated from the time-series standard deviation of returns for each fund. In finding better performance for larger funds, their results

\footnotetext{
${ }^{12}$ There are numerous examples, but perhaps the best known are the connections between Emory University and the founders of The Coca Cola Co. and the University of Rochester and the founder of Eastman Kodak Co.
} 
mirror those in our Table 3, which also shows net-of-market returns without risk adjustment and finds that larger endowments do better than smaller ones, but we come to a different conclusion below when we calculate risk-adjusted returns in our four-factor model. ${ }^{13}$ We note again that larger endowments are much more likely to report observations for 2009 and 2010, the earliest years in our sample, which are also the years in which endowments generally did best compared to the market averages (see Table A3).

As noted in Section II above, our calculation of annual percentage investment returns for each fund is based on an assumption that inflows of gifts and bequests occur halfway through the fiscal year, and outflows of distributions also occur halfway through the year, so we calculate the return by dividing net investment gains by the sum of beginning-of-year assets plus half of new contributions minus half of distributions. A more aggressive estimate would assume that all distributions occur at the beginning of the year while gifts are received at year-end, in which case the denominator would equal start-of-year assets minus distributions. The most conservative estimate would make the opposite assumptions, that gifts occur at the beginning of the year and that distributions are made at year-end, which would change the denominator to start-of-year assets plus $100 \%$ of contributions. We test whether our results change materially under either of these extreme assumptions, keeping the original cut-off limits for extreme outliers. In the first case, the median portfolio return of $2.57 \%$ in the bottom row of Table 3 would increase to $2.92 \%$, while in the second case it would drop to $2.41 \%$, implying a range of less than $+/-40$ basis points depending upon the assumption chosen, a magnitude far below the levels of

\footnotetext{
${ }^{13}$ Although we have a similar sample, we are unable to replicate the Sharpe ratio results reported by Lo, Matveyev and Zeume (2020), particularly the rank-ordering of Sharpe ratios across different quintiles of endowment size. These Sharpe ratio calculations are sensitive to choices made in the sample construction; our Sharpe ratio calculations change materially based on whether we use backfilled lagged and interior observations, as detailed in Appendix 1, and whether we omit the unusual year 2009, which consists entirely of backfilled observations that are reported more frequently by larger endowments. It is not clear whether backfilled observations are used by those authors. Our own calculations of risk-adjusted returns exhibit little variation if we omit all backfilled observations or only those for the year 2009.
} 
underperformance documented in the right column of Table 3. The impact on the alpha estimates in Table 4 is only minor. The four-factor alpha of -39 basis points shown in the first column of Table 4 is -33 basis points under the former, aggressive measure and moves to -41 basis points under the latter, conservative measure. Other results shown in Tables 3 and 4 exhibit only similarly tiny differences under either alternative assumption.

\section{Comparison of results with studies based on NACUBO sample}

As noted in the introduction, most earlier research into endowments' investment returns has used NACUBO's annual reports on higher education endowments. NACUBO relies on voluntary participation by colleges, universities, and research institutions. As recounted in the Foreword to the executive summary of NACUBO’s 1988 study, its annual endowment survey began in 1971 when NACUBO took over a project previously housed within the administration of Dartmouth College. In 1988 NACUBO’s annual reports began disclosing identities of participating endowments, which numbered 315 at that time. In 2009 NACUBO merged its study with similar research by Commonfund, resulting in a larger sample size and a change in the format of its annual reports. In 2018 TIAA replaced Commonfund as sponsor and the study was renamed and the annual reports again reformatted. ${ }^{14}$ By 2020 the sample size had dropped to 705 , continuing a pattern of attrition experienced since 2010 , when it peaked at 850 .

Along with the gradual reduction in sample size, we find considerable entry and exit from the NACUBO sample on a year-to-year basis; during our sample period of 2009-18, a total of 425 institutions drop out of the NACUBO sample after appearing in the previous year (some

\footnotetext{
${ }^{14}$ See the press release describing the reorganization at https://www.tiaa.org/public/about-tiaa/news-press/pressreleases/pressrelease705.html. Past NACUBO reports are available at the organization's data archive, https://www.nacubo.org.
} 
later rejoin), while 385 new institutions opt into the sample after not appearing the prior year (579 appear continuously in all ten years). This leads to a net decline in sample size of 40 , as the survey drops from 842 institutions in 2009 to 802 in 2018. In contrast, our sample size increases from 16,941 in 2009 to 25,621 in 2018, with the higher participation driven by the phase-in of IRS disclosure regulations. Once endowments begin reporting data to the IRS on Form 990, they should not drop out of our sample unless the endowment or its parent organization is dissolved and ceases to exist. ${ }^{15}$

Some researchers examining the NACUBO data during earlier sample periods have concluded that these higher education endowments earn returns above market benchmarks, and these studies have contributed to a widely held belief that non-profit endowments have been successful investors. For instance, Lerner, Schoar and Wang (2008, Figure 1) show that on average, endowments in the NACUBO sample out-perform the S\&P500 index during the 19932005 sample period of their study. Similarly Binfarè et al. (2020, Table 7) find that NACUBO endowments on average outperform a 50/30/20 benchmark of indexes for public equity, fixed income, and international equity during their 2004-2015 sample period.

However, other studies that calculate excess endowment returns for the NACUBO sample on a risk-adjusted basis have come to less favorable conclusions. Brown, Garlappi and Tiu (2007) find that estimated alphas in a four-factor model (similar to the model we estimate) are not statistically significant for the NACUBO endowments during their 1989-2005 estimation period. A similar 1992-2011 study by Barber and Wang (2013) using NACUBO data finds "no

\footnotetext{
${ }^{15}$ An exception could occur if an organization reverted to paper filing, but we are likely to capture most such observations through the use of lagged data in subsequent electronic filings. IRS regulations require electronic filing if the organization has total assets of at least $\$ 10$ million and files at least 250 returns annually, including income tax, excise tax, employment tax and information returns (such as Forms W-2 and 1099 reporting employee compensation).
} 
evidence that the average endowment is able to deliver alpha relative to public stock/bond benchmarks."

Our study, which finds significantly negative alphas for endowment returns between 2009-18, is sharply at odds with the results of earlier research that finds either positive or statistically insignificant excess returns in the NACUBO sample. Potential explanations for our different conclusions would include the slightly later sample period of our study, our vastly larger sample size and inclusion of industry sectors other than just higher education, and methodological differences including the choices of benchmarks, measurement of fiscal years, and self-selection of endowments that opt into the NACUBO sample. While we investigate a number of these possible explanations, as described more fully below, we believe our results closely agree with data reported in recent years by NACUBO itself, which indicate a marked downturn in the success of college and university endowments' investments over the past decade.

In NACUBO’s 2018 report, data on pages 10-11 report average annual returns of 5.8\% over the prior 10 years for 637 endowments in that year's sample; the comparable five-year and three-year average annual returns were $7.3 \%$ and $6.2 \%$, respectively, for samples of 732 and 749 endowments. These are far below the annual returns on the S\&P500 Index of 10.2\%, 13.4\%, and $11.9 \%$ for the prior ten-year, five-year, and three-year periods, respectively, as shown in a table on page 4 of the same report. For fixed income (Bloomberg Barclays Aggregate Bond Index) and private equity / venture capital (Burgiss Private Equity), the ten-year average annual returns were 3.7\% and 9.7\%, respectively. In other words, over the 2009-18 decade NACUBO’s endowment funds earned not much more than an investment in the fixed income index and were far behind the indexes for public and private equity. We believe these findings are completely 
consistent with our study's results, which show significant underperformance by a much larger sample of endowments between 2009-18 with overall returns not much higher than the index of U.S. Treasuries. These findings are reinforced by NACUBO's 2018 report, in which a graph on page 12 shows the NACUBO endowments underperforming their own internal targets (generally in the $7 \%$ range) in every one of the years between $2009-18 .{ }^{16}$

We attempt to apply our study's methodology to the endowments in the NACUBO sample but run into a number of problems. The parent organizations for certain endowments covered by NACUBO, especially state universities and religious institutions, are not required to file Form 990 with the IRS, so they cannot appear in our sample. NACUBO also uses benchmarks that assume all endowments have a June 30 fiscal year and encourages them to report data on this basis, ${ }^{17}$ but in reality only $41 \%$ of endowments' years end on June 30 , and the majority report to the IRS on the basis of other time periods. Although NACUBO provides a list of participating institutions, not all of them are included in its calculations of overall investment returns, with some endowments only providing data about other categories such as asset

\footnotetext{
${ }^{16}$ Recent NACUBO data, generated beyond the end of our sample period, indicates that higher education endowment performance has only worsened relative to market benchmarks. In the year ended June 30, 2020, NACUBO's most recent report indicates an average $1.8 \%$ return for the 705 endowments in its sample, compared to 7.5\% earned by the S\&P500 equity index and 8.7\% earned by the Bloomberg Barclays U.S. Aggregate bond index. Much of the underperformance appears to be due simply to poor stock picking, as the average U.S. equity return for the funds in the sample was 4.0\%, well below the market. For the year ended June 30, 2019 the higher education endowments' results weren't much better, as NACUBO reported an average endowment return of 5.3\%, compared to the U.S. equity and bond market returns of $10.4 \%$ and $7.9 \%$, respectively.

${ }^{17}$ We cannot tell how many institutions with different fiscal years actually comply with NACUBO's request to adjust their annual reporting periods to June 30. In its 2007 Executive Summary, NACUBO writes, "NACUBO again encouraged participants to report their investment pool data on the basis of a June 30 fiscal year-end date. NACUBO hopes that in the future all participant institutions will provide data based on June 30 to allow for the highest level of comparability. .." The language, which suggests incomplete compliance by reporting members, does not appear in subsequent reports.
} 
allocation. ${ }^{18}$ This incomplete participation would tend to exacerbate the year-to-year changes in NACUBO's sample discussed above.

While we are unable to replicate our overall results within the NACUBO sample, we undertake additional analysis to assess whether differences exist between the entire non-profit universe covered by our study and the smaller, more focused higher education segment from which NACUBO draws its observations. Table 5 presents the average alphas that we estimate for colleges and universities compared to non-profits in other sectors, using the same method as Table 4.

Estimates in Table 5 indicate a negative performance gap between the higher education sector and all other non-profits: higher education institutions, whose endowments account for more than half of all assets in the sample despite representing just $5 \%$ of the observations, are estimated to have abnormal investment returns of minus 64 basis points per year, while all other (non-higher education) endowment funds earn negative alphas of lower magnitude, minus 38 basis points per year. However, this result appears to be size-driven, as college and university endowments are over-represented in the larger endowment size cohorts, which underperform smaller endowments during our sample period as shown in Table 4 (Lo, Matveyev, and Zeume (2020) also find that size-adjustment washes out evidence of significant performance differences by higher education adjustments, although their result is in the opposite direction from ours). Following studies such as Lerner, Schoar and Wang (2008), we look at the abnormal returns earned by endowments of the top 50 national universities as ranked in 2021 by U.S. News

\footnotetext{
${ }^{18}$ For instance, in its 2009 Executive Summary, NACUBO writes, "Of the 842 institutions participating in the year's Study, 94 percent - or 794 institutions - provided return data for the most recent fiscal year.” In 2010, a similar disclosure indicates that only 817 of the 850 "participating" institutions had actually provided return data. NACUBO does not identify which endowments withhold data, and it discontinued providing information about the numbers of such endowments beginning with its 2013 report. In one report NACUBO listed the names of a smaller number of institutions than the number it identified as participating.
} 
and World Report. These highly ranked schools earn minus 206 basis points per year, a result that supports a conclusion that the investment wisdom of top universities today amounts to little more than a myth. Frequent mentions in the media of the out-performance of top schools may be due to the publicity about the success of just one university, Yale (see Phalippou, 2013), and the struggles of the Harvard University endowment and others in recent years have been well chronicled by the news media. ${ }^{19}$ In addition, we compare NACUBO and non-NACUBO institutions' alphas in the right two columns of Table 5. We count a college or university as a NACUBO participant if its endowment appears in the NACUBO study at any time between 2009-18, which captures 909 institutions, while there are a further 608 higher education institutions that do not participate in NACUBO during this time..$^{20}$ The NACUBO participants have very negative alphas, estimated at minus 113 basis points per year, compared to the nonNACUBO institutions, which have estimated alphas of minus 6 basis points, not statistically significant. These estimates belie any possibility of sample selection into the NACUBO study by strongly performing endowments, an issue we investigate further below. We conjecture that the poor results for NACUBO schools are probably in line with the overall negative sizeperformance effect shown in Table 4 above, since larger colleges and universities are overrepresented in NACUBO relative to smaller ones.

\footnotetext{
${ }^{19}$ See, for example, McDonald, "Harvard Investing Chief Is Disappointed with Fund's Performance,” Bloomberg Markets, October 24, 2019, available at https://www.bloomberg.com/news/articles/2019-10-24/harvard-investingchief-is-disappointed-with-fund-s-performance, as well as McDonald and Lorin, "Ivy League Investment Strategy Loses Luster in Disappointing Year,” Bloomberg Markets, October 17, 2019, available at https://www.bloomberg.com/news/articles/2019-10-17/ivy-league-endowment-strategy-loses-luster-indisappointing-year. The latter article quotes the endowment manager at a smaller college assessing the record of elite universities: "They’re underperforming and their expenses are extra high with alternative investments."

${ }^{20}$ The total number of observations in the right two columns of Table 5 exceeds the number of observations for colleges and universities in the second column. This occurs because the sample in the second column is identified by the NTEE higher education sector classification, while the NACUBO sample includes a number of additional non-profits that are not classified as higher education institutions by NTEE.
} 
The possibility that sample selection bias influences NACUBO's results has been the object of speculation in numerous academic studies. ${ }^{21}$ Brown, Garlappi, and Tiu (2007) and Barber and Wang (2013) both contain thoughtful discussions of the issue as well as some indirect evidence that tends to suggest that selection bias has little or no importance. Until now, directly studying the presence of selection bias in NACUBO has not been possible, since researchers have not been able to observe the endowment returns of institutions that don't opt in to NACUBO’s sample.

We conduct regression analysis within the sample of NACUBO endowments to assess whether their first years in the sample exhibit abnormally strong performance, which would be consistent with above-average funds opting into the sample, and we also test whether performance is abnormally poor in those years in which endowments drop out of NACUBO. We exclude sample entrants during the year 2009, since NACUBO’s merger of its study with Commonfund's that year greatly increased its sample size. The results, which we do not tabulate in order to save space, show no significant performance differences for these subsets of entering and exiting endowment observations. This failure to reject the null hypotheses is consistent with an absence of selection bias in the overall NACUBO sample.

\section{Distribution policy}

\footnotetext{
${ }^{21}$ NACUBO's annual studies say little about the issue of selection bias. The cooperation rate of potential survey participants appears to have been last mentioned in the 2008 Executive Summary, when NACUBO wrote 1,028 institutions were "invited to participate" in the study and 796 agreed, a cooperation rate of $77 \%$. We are unable to locate similar information in later reports. The reports generally contain oblique language about sample recruitment that makes no mention of cooperation issues or the declining sample size experienced since 2010. For instance, the 2017 report states only that "The design of the 2017 [study] took place in the spring and early summer of 2017. Web-enabled questionnaires and field interviews followed in the third and fourth quarters of calendar 2017." Identical language appears in many previous reports.
} 
Endowments exist to distribute funds to their parent organizations. In principle, these distributions could fund part of an organization's operating budget on a recurring basis, or be used for non-recurring capital expenditures, or could occur as needed to close unexpected deficits. Little is known about the distribution policies for non-profit endowments other than two recent small-sample studies by Brown et. al (2014) and Yermack (2017) which appear to reach opposite conclusions. Brown et. al study approximately 200 large research universities and find a surprisingly pro-cyclical distribution pattern, in which universities experiencing negative financial shocks reduce their endowment payouts. Yermack (2017) studies 120 large art museums and finds that endowment withdrawals increase when the museums' operating surpluses decline.

Numerous papers beginning with Tobin (1974) have proposed spending policies for endowments, and Brown et. al (2014) provide an excellent review of this literature. Many of these rules resemble the consumption-smoothing predictions of Tobin's permanent income hypothesis or the dividend-smoothing payout rules followed by corporations as first documented by Lintner (1956). The tenor of these policies implies that a non-profit aims for a stable distribution rate from its endowment, with the rate equal to the long-run expected return of the fund. However, other papers have taken issue with this type of distribution policy, such as Hansmann (1990) and Merton (1993). Hansmann focuses on issues of intergenerational equity and concludes that an overly conservative distribution policy may give undue benefit to more affluent future generations. Merton notes that an endowment fund can be invested, and can follow distribution policies, that hedge an organization's cash flows from other assets, such as a university's streams of tuition revenue and donations. He would therefore expect a countercyclical distribution policy. 
Table 6 shows descriptive statistics about the distribution policies for the endowment funds in our sample. We calculate the distribution rate based on information in Part V, Schedule D of Form 990. The distribution rate equals the ratio of distributions for grants and scholarships (Line 1d) plus distributions for facilities and programs (Line 1e) over the sum of beginning-ofyear assets (Line 1a) plus 50\% of new contributions and transfers during the year (Line 1b). It should be thought of as similar to the dividend policy for a company deciding what fraction of its equity to pay out to shareholders each year. We present data for the sample overall in the left column of Table 6 and for each of the four size cohorts in the next four columns. The data indicate that endowments have a mean distribution rate of $5.88 \%$ and a median rate of $1.73 \%$, with more than $40 \%$ of funds not making any distribution at all. Analysis of the size cohorts reveals a clear connection between endowment size and payout policies. In the second column of Table 6, data indicate that most large endowment funds have very stable distribution policies, with mean and median distribution ratios of $4.87 \%$ and $4.35 \%$, respectively, and more than $95 \%$ of all funds making a distribution in a given year. ${ }^{22}$ In the right column of Table 6 , the data indicate that the majority of tiny endowment funds make no distribution at all. The other two size cohorts see the data trend monotonically between these two extremes.

The data suggest that smaller endowments follow an accumulation strategy, with a predisposition to make no distributions to their parent organizations, and they instead attempt to grow to a critical mass. Once endowments have grown large, they follow very different distribution strategies. The mean and median distribution rates for large endowments are very close, in the neighborhood of 4.5\%. Extraordinary distributions from larger endowments seem to

\footnotetext{
${ }^{22}$ For comparison, Brown et. al's (2014) survey of about 200 large universities drawn from the NACUBO sample between 1986-2009 shows mean and median payout rates of 5.2\%, calculated with slightly different methodology than ours. Yermack's (2017) study of 120 art museums between 2008-2013 shows mean and median spending rates of $5.8 \%$ and $4.7 \%$, respectively.
} 
be rare, since the mean and median withdrawal rates are almost equal, and virtually all large funds make at least some distribution. In contrast, the mean distribution for tiny endowments is 6.28\%, even though more than half make no distribution at all. This implies that smaller funds are accessed from time to time for large extraordinary withdrawals.

The $4.5 \%$ distribution rate appears to be a focal point that is commonly used by many large, established funds. This figure may approximate the real return that one might expect from a fund invested $60 \%$ in equities and $40 \%$ in risk-free debt, but if inflation is greater than zero, the 4.5\% nominal distribution rate is likely to be less than the return of a typical fund, meaning that endowments will tend to grow over time. ${ }^{23}$ This conservative distribution policy has been the focus of much of the external criticism that has focused especially on the growth of elite universities' endowments and contributed to Congress's decision to enact a $1.4 \%$ tax on certain universities' net investment income beginning in 2018 (the tax was initially estimated to affect about 40 institutions). By comparison, private foundations are generally required to distribute at least $5.0 \%$ of their assets in order to maintain their non-profit status, and that number also has drawn criticism for being below the likely investment returns for funds held in these entities.

Table 7 presents a regression analysis of annual endowment distributions as a function of six potential sources of cash for the organization: operating income, cash on the balance sheet at the start of the year, new donations, new government grants, an increase in debt, and investment earnings of the endowment itself. We include fixed effects for each endowment. Standard errors are clustered by endowment, and we show estimates for the overall sample and for each of the four size cohorts. We exclude from this analysis observations for lagged investment performance that are reported on Schedule D, Part V of Form 990, since we lack annual

\footnotetext{
${ }^{23}$ Hansmann (1990, pp 9-10) writes, "nearly all discussions of spending rules simply take it for granted that the rate of spending out of endowment should not, over time, exceed the real rate of return on the investments constituting the endowment."
} 
operating data for many of these lagged observations. We also exclude organizations that identify themselves as "Supporting Public Charities" (coded as S for the NTEE classification variable "Level 2"). These are typically organizations affiliated with other non-profits, and they usually hold or manage the other organization's endowment funds but have few if any operating expenses of their own.

In the left column of Table 7, estimates indicate that the dollar value of endowment distributions exhibits a negative association of -0.04 with an organization's operating surplus, which appears to be influenced almost entirely by an estimate of -0.09 for the largest size cohort, endowments above $\$ 100$ million. This implies that about nine cents per dollar of operating shortfalls are covered by increased endowment distributions in large non-profits, an estimate similar to Yermack's (2017) estimate of 13 cents per dollar for prominent art museums. This result seems to contradict Brown et. al's finding that endowment payouts are reduced when an organization experiences negative financial shocks. However, that paper takes a different empirical approach, defining a "shock" not in terms of operating losses, but instead as a deterioration in the ratio of endowment assets over total expenses. Most other estimates in Table 7 are not statistically significant.

\section{Endowment performance and its impact on fundraising}

Given the high public interest in the investment performance of endowment funds, a natural hypothesis to examine is whether donors respond to successful years in which funds earn strong investment returns. We test this hypothesis in regressions analysis shown in Table 8. The dependent variable in this table is based on total donations during the fiscal year. We calculate this from Part VIII of Form 990 as the sum of federated campaigns (Line 1a) plus fundraising 
events (Line 1c) plus all other contributions, gifts, and grants (Line 1f). We do not include membership dues (Line 1b), income from related organizations (Line 1d) or government grants (Line 1e). Our dependent variable in Table 8 is then $\ln \left(\right.$ donations $_{t} /$ donations $\left._{t-1}\right)$, and we regress this against the endowment investment return for the prior year with results shown in the left column. In the center column, we repeat this regression and also include the equity market index. In the right column, we include the return on the 60-40 balanced portfolio of the equity and Treasury bond indexes introduced as a benchmark in Table 3 above. We lack a sufficient number of annual observations for each fund to fit a more elaborate model of expected returns, and all explanatory variables are compounded continuously so that we can interpret their coefficients as elasticities. We include endowment fixed effects and cluster standard errors at the endowment level.

Results in Table 8 indicate a positive association between new donations and the prior year's endowment return. In column one, we obtain a statistically significant estimate of about 0.21 when the endowment return enters the model alone. This estimate drops to 0.07 and becomes insignificant when the overall market return is included in the second column, and it rises to 0.11 and is again significant when the $60-40$ balanced portfolio return is included in the third column. These estimates imply a modest positive elasticity between investment performance and the willingness of donors to contribute in future periods. If a fund out-performs the $60-40$ benchmark by $10 \%$, for instance, donations would grow by about $1.1 \%$ in the following year, all else equal. Donation increases also appear to respond positively to appreciation of the broad market indices, holding constant the endowment's return. These results parallel those found in other "flow-to-performance" studies in the asset management industry that document increased inflows of new capital after years in which a money manager 
outperforms market benchmarks. Lewellen and Lewellen (2018) provide a recent contribution in this area and a review of the lengthy literature. Similarly, Lo, Matveyev, and Zeume (2020) study the related hypothesis of whether endowment contributions increase when the equity market benchmark index is rising, and they find evidence in support. That study does not examine overall donations to the endowments' parent firms, nor does it investigate the importance of each organization's endowment return instead of the overall market return.

\section{Discussion and conclusions}

We study the investment returns and distribution policies of non-profit endowment funds, which have grown by 2018 into a $\$ 0.78$ trillion institutional investor class in the U.S. economy. Up to now, nearly all research on endowments has focused on the NACUBO sample of major colleges and universities, using self-reported survey data from about 800 organizations. Although higher education endowments represent somewhat more than half of the total asset class, our results suggest that the research focus on them may be somewhat misleading, as they have inferior investment performance on an absolute basis and also when compared to endowments with parent organizations in other sectors.

In a sample of more than 35,000 endowment funds drawn from U.S. Internal Revenue Service filings, our regression analysis indicates that on average, endowment funds underperform their market benchmarks significantly. This pattern is influenced by an endowment's size, as larger endowments tend to underperform the most on a risk-adjusted basis, even though the larger funds earn higher raw returns. Our performance results must be viewed in the context of the unusual market behavior at the start of our 2009-2018 sample period, which began with a sharp decline in equity values during the global financial crises and was followed 
by a very strong market recovery that many endowments appear not to have fully participated in. These market movements are widely viewed as exceptional, and it is certainly possible that endowments have achieved better investment performance in the past and may do so again in the future in more ordinary market environments.

Most endowments appear to follow distribution policies that are quite conservative, with a median payout ratio of about $1.7 \%$ of their assets. Again, size plays a big role, as most tiny endowments make no distributions at all, and larger endowments tend to cluster around a distribution rate of about $4.5 \%$ of fair market value. This number would appear to resemble the expected long-run real return on a fund that is invested $60 \%$ in equities and $40 \%$ in debt.

We find an interesting connection between an endowment's investment performance and the willingness of donors to change their contributions in future years. We estimate an elasticity between investment returns and the growth of donations of approximately 0.20 . This implies that the constituent donors of a non-profit, such as the alumni of a university, are aware of how well the organization performs as an investor and adjust their donations in a pattern that rewards stock market profits with a supply of new capital, much as one sees the inflows to a mutual fund increase when the fund outperforms the market. 


\section{Bibliography}

Barber, Brad M., and Terrance Odean, 2000, Trading is hazardous to your wealth: The common stock investment performance of individual investors, Journal of Finance 55, 773-806.

Barber, Bard M., and Guojun Wang, 2013, Do (some) university endowments earn alpha? Financial Analysts Journal 69, 26-44.

Binfarè, Matteo, and Robert S. Harris, 2020, Does chief investment officer pay reflect performance? Evidence from non-profits, unpublished working paper, available at ssrn.com/abstract $=3504212$.

Brown, Jeffrey R., Steven G. Dimmock, Jun-Koo Kang, and Scott J. Weisbenner, 2014, How university endowments respond to financial market shocks: Evidence and implications, American Economic Review 104, 931-962.

Brown, Keith C., Lorenzo Garlappi, and Cristian Tiu, 2007, The troves of academe: Asset allocation, risk budgeting and the investment performance of university endowments funds, unpublished working paper, available at ssrn.com/abstract=981436.

Brown, Keith C., Lorenzo Garlappi, and Cristian Tiu, 2010, Asset allocation and portfolio performance: Evidence from university endowment funds, Journal of Financial Markets 13, 268294.

Brown, Stephen, William N. Goetzmann, and Roger G. Ibbotson, 1999, Offshore hedge funds: Survival and performance, Journal of Business 72, 91-117.

Cejnek, Georg, Richard Franz, Otto Randl, and Neal Stoughton, 2014, A survey of university endowment management research, Journal of Investment Management, third quarter 2014.

Chen, Joseph, Harrison Hong, Ming Huang, and Jeffrey D. Kubik, 2004, Does fund size erode mutual fund performance? The role of liquidity and organization, American Economic Review 94, 1276-1302.

Fama, Eugene F., and Kenneth R, French, 2010, Luck versus skill in the cross-section of mutual fund returns, Journal of Finance 65, 1915-1947.

Franzoni, Francesco, Eric Nowak, and Ludovic Phalippou, 2012, Private equity performance and liquidity risk, Journal of Finance 67, 2341-2373.

Hansmann, Henry, 1990, Why do universities have endowments? Journal of Legal Studies 19, 342.

Kosowski, Robert, Allan Timmerman, Russ Wermers, and Hal White, 2006, Can mutual fund "stars" really pick stocks? New evidence from a bootstrap analysis, Journal of Finance 61, 25512595. 
Lerner, Josh, Antoinette Schoar, and Jialan Wang, 2008, Secrets of the academy: The drivers of university endowment success, Journal of Economic Perspectives 22, 207-222.

Lewellen, Jonathan, and Katharina Lewellen, 2018, Institutional investors and corporate governance: The incentive to be engaged, unpublished manuscript, Dartmouth Tuck School of Business, available at https://ssrn.com/abstract=3265761.

Lintner, John, 1956, Distribution of incomes of corporations among dividends, retained earnings, and taxes, American Economic Review 46, 97-113.

Lo, Andrew, Egor Matveyev, and Stefan Zeume, 2020, The risk, reward, and asset allocation of nonprofit endowment funds, unpublished manuscript, MIT Sloan School of Management, available at https://ssrn.com/abstract $=3560240$.

Merton, Robert, 1993, Optimal investment strategies for university endowment funds in Charles T. Clotfelter and Michael Rothschild eds., Studies of Supply and Demand in Higher Education (University of Chicago Press), 211-242.

Phalippou, Ludovic, 2013, Yale’s endowment returns: Case study in GIPS interpretation difficulties, Journal of Alternative Investments 15(4), 97-103.

Pollet, Joshua M., and Mungo Wilson, 2008, How does size affect mutual fund behavior? Journal of Finance 63, 2941-2969.

Tobin, James, 1974, What is permanent endowment income? American Economic Review 64, 427-432.

Yermack, David, 2017, Donor governance and financial management in prominent U.S. art museums, Journal of Cultural Economics 41, 215-235. 


\section{Table 1}

\section{Sample of Form 990 filings}

The table shows the sample of Internal Revenue Service Form 990 filings that we retrieve from Amazon Web Services. We retain all observations that have non-missing, positive values for endowment assets at the start and end of the year and exhibit no contradictions or inconsistencies in Table V, Schedule D, where the endowment data is reported. Certain duplicate filings for the same organization are dropped according to a procedure described in the text. Observations are classified according to each organization's National Taxonomy of Exempt Entities (NTEE) code.

Panel A: Number of unique Form 990 filers by year and NTEE code

Year
2009
2010
2011
2012
2013
2014
2015
2016
2017
2018
Total

$\begin{array}{cc}\begin{array}{c}\text { Arts, culture, } \\ \text { and } \\ \text { humanities }\end{array} & \begin{array}{c}\text { Higher } \\ \text { education }\end{array} \\ 1,938 & 1,124 \\ 2,759 & 1,194 \\ 3,269 & 1,222 \\ 3,500 & 1,238 \\ 3,648 & 1,253 \\ 3,760 & 1,259 \\ 3,853 & 1,256 \\ 3,878 & 1,242 \\ 3,904 & 1,229 \\ 3,769 & 1,206 \\ 34,278 & 12,223\end{array}$

$\begin{array}{cc}\begin{array}{c}\text { Education } \\ \text { (other) }\end{array} & \text { Hospitals } \\ 2,729 & 877 \\ 3,841 & 1,012 \\ 4,663 & 1,050 \\ 4,928 & 1,046 \\ 5,160 & 1,073 \\ 5,349 & 1,068 \\ 5,449 & 1,040 \\ 5,435 & 1,005 \\ 5,405 & 981 \\ 5,260 & 925 \\ 48,219 & 10,077\end{array}$

$\begin{array}{ccc}\begin{array}{c}\text { Environment } \\ 770\end{array} & \begin{array}{c}\text { Health } \\ \text { (other) }\end{array} & \begin{array}{c}\text { Human } \\ \text { services }\end{array} \\ 1,074 & 2,228 & 4,229 \\ 1,241 & 3,191 & 5,679 \\ 1,341 & 3,340 & 6,400 \\ 1,419 & 3,437 & 7,102 \\ 1,470 & 3,553 & 7,349 \\ 1,510 & 3,573 & 7,517 \\ 1,530 & 3,517 & 7,537 \\ 1,556 & 3,453 & 7,487 \\ 1,495 & 3,234 & 7,094 \\ 13,406 & 32,402 & 67,198\end{array}$

$\begin{array}{ccc}\text { International } & \begin{array}{c}\text { Mutual } \\ \text { benefit }\end{array} & \begin{array}{c}\text { Public and } \\ \text { societal } \\ \text { benefit }\end{array} \\ 228 & 244 & 1,837 \\ 307 & 348 & 2,529 \\ 361 & 404 & 2,944 \\ 379 & 423 & 3,160 \\ 403 & 450 & 3,293 \\ 415 & 463 & 3,457 \\ 429 & 501 & 3,538 \\ 425 & 530 & 3,560 \\ 426 & 510 & 3,508 \\ 404 & 486 & 3,349 \\ 3,777 & 4,359 & 31,175\end{array}$

Religion
342
500
574
627
669
704
724
715
711
674
6,240

Unknown

or missing Total

$389 \quad 16,935$

$458 \quad 22,577$

$391 \quad 25,710$

$276 \quad 27,062$

$167 \quad 28,074$

$120 \quad 28,967$

$79 \quad 29,469$

$76 \quad 29,450$

$96 \quad 29,266$

$142 \quad 28,038$

$2,194 \quad 265,548$


Panel B: Beginning-of-year endowment assets (\$million) by year and NTEE code

\begin{tabular}{|c|c|c|c|c|c|c|c|c|c|c|c|c|c|}
\hline Year & $\begin{array}{c}\text { Arts, } \\
\text { culture, and } \\
\text { humanities }\end{array}$ & $\begin{array}{l}\text { Higher } \\
\text { education }\end{array}$ & $\begin{array}{l}\text { Education } \\
\text { (other) }\end{array}$ & Hospitals & Environment & $\begin{array}{l}\text { Health } \\
\text { (other) }\end{array}$ & $\begin{array}{l}\text { Human } \\
\text { services }\end{array}$ & International & $\begin{array}{l}\text { Mutual } \\
\text { benefit }\end{array}$ & $\begin{array}{c}\text { Public and } \\
\text { societal } \\
\text { benefit }\end{array}$ & Religion & $\begin{array}{l}\text { Unknown } \\
\text { or missing }\end{array}$ & Total \\
\hline 2009 & $\$ 29,275$ & $\$ 297,845$ & $\$ 65,071$ & $\$ 28,996$ & $\$ 5,727$ & $\$ 14,410$ & $\$ 15,519$ & $\$ 2,912$ & $\$ 2,113$ & $\$ 22,672$ & $\$ 1,262$ & $\$ 1,967$ & $\$ 487,770$ \\
\hline 2010 & $\$ 26,780$ & $\$ 230,700$ & $\$ 67,976$ & $\$ 30,933$ & $\$ 6,021$ & $\$ 15,266$ & $\$ 17,338$ & $\$ 4,145$ & $\$ 2,386$ & $\$ 27,647$ & $\$ 1,987$ & $\$ 1,908$ & $\$ 433,086$ \\
\hline 2011 & $\$ 32,511$ & $\$ 250,409$ & $\$ 76,726$ & $\$ 35,630$ & $\$ 6,721$ & $\$ 18,264$ & $\$ 19,582$ & $\$ 4,782$ & $\$ 2,648$ & $\$ 30,953$ & $\$ 2,393$ & $\$ 1,898$ & $\$ 482,516$ \\
\hline 2012 & $\$ 36,543$ & $\$ 297,713$ & $\$ 91,220$ & $\$ 36,696$ & $\$ 7,610$ & $\$ 21,328$ & $\$ 21,391$ & $\$ 5,318$ & $\$ 2,757$ & $\$ 39,575$ & $\$ 2,715$ & $\$ 1,609$ & $\$ 564,476$ \\
\hline 2013 & $\$ 37,448$ & $\$ 295,352$ & $\$ 93,436$ & $\$ 39,724$ & $\$ 8,106$ & $\$ 23,363$ & $\$ 22,869$ & $\$ 5,842$ & $\$ 2,953$ & $\$ 45,372$ & $\$ 3,212$ & $\$ 1,135$ & $\$ 578,814$ \\
\hline 2014 & $\$ 42,919$ & $\$ 323,335$ & $\$ 106,618$ & $\$ 43,239$ & $\$ 8,982$ & $\$ 26,472$ & $\$ 25,488$ & $\$ 7,608$ & $\$ 2,824$ & $\$ 54,302$ & $\$ 3,748$ & $\$ 1,662$ & $\$ 647,198$ \\
\hline 2015 & $\$ 46,950$ & $\$ 368,468$ & $\$ 111,068$ & $\$ 45,902$ & $\$ 9,767$ & $\$ 28,435$ & $\$ 27,692$ & $\$ 8,486$ & $\$ 3,153$ & $\$ 59,439$ & $\$ 4,129$ & $\$ 1,458$ & $\$ 714,947$ \\
\hline 2016 & $\$ 47,355$ & $\$ 381,133$ & $\$ 115,613$ & $\$ 45,517$ & $\$ 9,652$ & $\$ 28,392$ & $\$ 27,262$ & $\$ 5,493$ & $\$ 2,938$ & $\$ 62,530$ & $\$ 2,605$ & $\$ 1,560$ & $\$ 730,051$ \\
\hline 2017 & $\$ 42,944$ & $\$ 367,739$ & $\$ 115,781$ & $\$ 47,442$ & $\$ 9,679$ & $\$ 28,387$ & $\$ 27,277$ & $\$ 5,456$ & $\$ 3,032$ & $\$ 62,436$ & $\$ 2,660$ & $\$ 1,873$ & $\$ 714,707$ \\
\hline 2018 & $\$ 46,695$ & $\$ 400,659$ & $\$ 126,878$ & $\$ 50,773$ & $\$ 10,749$ & $\$ 27,580$ & $\$ 29,533$ & $\$ 6,335$ & $\$ 3,076$ & $\$ 68,651$ & $\$ 2,820$ & $\$ 2,955$ & $\$ 776,706$ \\
\hline Total & $\$ 389,421$ & $\$ 3,213,352$ & $\$ 970,388$ & $\$ 404,850$ & $\$ 83,015$ & $\$ 231,897$ & $\$ 233,952$ & $\$ 56,378$ & $\$ 27,881$ & $\$ 473,578$ & $\$ 27,531$ & $\$ 18,026$ & $\$ 6,130,270$ \\
\hline
\end{tabular}




\section{Table 2}

\section{Descriptive statistics}

The table shows descriptive statistics for a sample of 35,755 U.S. non-profit organizations between 2009-2018. Data are obtained from Internal Revenue Service Form 990 filings, and all dollar values are in \$millions. Panel A shows annual observations for endowment funds, and the number of observations is greater than for other panels because of the inclusion of up to four years of historical lagged endowment data available on Schedule D of Form 990. Endowment assets at the start of year are reported in Part V of Schedule D (Line 1a). Endowment additions appear on Line 1b, and the endowment distribution rate equals the sum of grants and scholarships (Line 1d) and other expenditures for facilities and programs (Line 1e) divided by start-of-year endowment assets plus 0.5 times endowment contributions. Net investment return equals net endowment investment gains/losses (Line 1c) minus any

administrative expenses (Line 1f), divided by start of year endowment assets plus 0.5 times endowment contributions (Line 1b) minus 0.5 times endowment distributions (Lines 1d and 1e). Panel B shows annual financial data for the endowments' parent organizations, and we exclude endowments that are classified as "supporting public charities" and are held in a separate legal entity than the operating affiliate. Total revenue is reported in Part I, Line 12. Total assets and liabilities are reported as of the start of the fiscal year in Part X, lines 16 and 26. Endowment distribution equals the sum of grants or scholarships (Line 1d) and other expenditures for facilities and programs (Line 1e) as reported in part V of Schedule D. Cash donations equal the sum of federated campaigns (Part VIII, Line 1a), fundraising events (Part VIII, Line 1c) and other gifts (Part VIII, Line 1f). Operating surplus equals program service revenue (Part VII, Line 2g) minus program service expenses (Part IX, Line 25). Endowment earnings is from part V of Schedule D (Line 1b). Net change in long-term debt equals the difference in bonds, loans, and notes outstanding at the end of year from the beginning of the year (sum of Line 20, Line 23, and Line 24 in Part X). Government grants received equal cash from newly awarded grants (Part VIII, Line 1e) minus changes in grants and pledges receivable (Part X, Line 3). Cash on the balance sheet is the sum of reported cash (Part X, Line 1) and savings (Part X, Line 2). 
Panel A: Endowment data

\begin{tabular}{|c|c|c|c|c|c|c|}
\hline Endowment assets & $\begin{array}{c}\text { Obs. } \\
265,548\end{array}$ & $\begin{array}{l}\text { Mean } \\
\$ 23.1\end{array}$ & $\begin{array}{c}\text { Median } \\
\$ 0.9\end{array}$ & $\begin{array}{c}\text { Std. Dev. } \\
\$ 350.4\end{array}$ & $\begin{array}{l}\text { Min. } \\
\$ 0.0\end{array}$ & $\begin{array}{c}\text { Max. } \\
\$ 36,428.5\end{array}$ \\
\hline Endowment additions & 265,548 & $\$ 0.9$ & $\$ 0.002$ & $\$ 12.1$ & $(\$ 25.8)$ & $\$ 1,415.7$ \\
\hline Endowment distribution rate & 265,548 & 0.0588 & 0.0173 & 0.1521 & 0 & 1.9992 \\
\hline Net investment return & 265,548 & 0.0444 & 0.0257 & 0.0834 & -0.5765 & 0.8197 \\
\hline \multicolumn{7}{|l|}{ Panel B: Financial data } \\
\hline & Obs. & Mean & Median & Std. Dev. & Min. & Max. \\
\hline Total revenue & 159,840 & $\$ 47.4$ & $\$ 3.2$ & $\$ 286.8$ & $(\$ 33.0)$ & $\$ 13,609.0$ \\
\hline Total assets & 159,840 & $\$ 91.7$ & $\$ 6.4$ & $\$ 788.0$ & $(\$ 22.7)$ & $\$ 75,287.5$ \\
\hline Total liabilities & 159,840 & $\$ 33.3$ & $\$ 0.6$ & $\$ 290,6$ & $(\$ 5.2)$ & $\$ 35,024.4$ \\
\hline Endowment distribution & 159,840 & $\$ 1.4$ & $\$ 0.01$ & $\$ 21.5$ & $\$ 0$ & $\$ 1,989.6$ \\
\hline Cash donations & 159,840 & $\$ 4.5$ & $\$ 0.5$ & $\$ 34.2$ & $(\$ 1.2)$ & $\$ 2,754.5$ \\
\hline Operating surplus & 159,840 & $(\$ 1.5)$ & $(\$ 0.3)$ & $\$ 60.3$ & $(\$ 2,764.8)$ & $\$ 1,498.8$ \\
\hline Endowment earnings & 159,840 & $\$ 2.3$ & $\$ 0.01$ & $\$ 45.9$ & $(\$ 602.9)$ & $\$ 5,394.7$ \\
\hline Net change in long-term debt & 159,840 & $\$ 0.5$ & $\$ 0$ & $\$ 17.6$ & $(\$ 926.6)$ & $\$ 2,052.6$ \\
\hline Government grants received & 159,840 & $\$ 2.6$ & $\$ 0.02$ & $\$ 27.3$ & $(\$ 305.4)$ & $\$ 1,334.5$ \\
\hline Cash on balance sheet & 159,840 & $\$ 6.2$ & $\$ 0.6$ & $\$ 44.1$ & $(\$ 415.5)$ & $\$ 2,972.8$ \\
\hline
\end{tabular}




\section{Table 3}

\section{Endowment returns}

The table shows summary statistics of net investment returns on endowment funds for a sample of 35,755 U.S. non-profit organizations between 2009-2018. Endowment data are obtained from Part V of Schedule D of Internal Revenue Service (IRS) Form 990 filings. The annual net investment return for each endowment fund is estimated as endowment investment gains/losses (Line 1c) net of any administrative expenses (Line 1f), divided by start of year endowment assets plus 0.5 times endowment contributions (Line 1b) minus 0.5 times endowment distributions (Lines $1 \mathrm{~d}$ and 1e). For comparison purposes, the table also shows mean benchmark returns based on the trailing 12-month returns on the Center for Research in Securities Prices (CRSP) value-weighted index, the CRSP 10 -Year U.S. Treasury Bond Index, and a "balanced portfolio" comprised of 60\% of the CRSP equity index and 40\% of the Treasury bond index. The right three columns show descriptive statistics for the difference between each endowment's return and the balanced portfolio for the same time period. Data in the table represent means and medians for 12-month reporting periods and should not be interpreted as compound annual returns for the 2009-2018 period. Observations are not uniformly distributed through time. Many endowments' 12-month reporting periods end in June or December, and the number of observations generally increases over time to reflect increasing compliance with IRS electronic filing requirements especially by smaller organizations. Each endowment is assigned to one of four size cohorts based on its average start-of-year assets across all observations. The weighted mean is calculated using start-of-year endowment assets (Line 1a) as the weighting factor within each size cohort as well as the full sample.

Endowment returns $\quad$ Benchmark returns

\begin{tabular}{|c|c|c|c|c|c|c|c|c|c|c|c|c|}
\hline $\begin{array}{l}\text { Large: } \\
\text { assets > \$100 mm }\end{array}$ & $\begin{array}{l}\text { Obs. } \\
7,589\end{array}$ & $\begin{array}{c}\text { Mean } \\
0.0597\end{array}$ & $\begin{array}{c}\text { Weighted } \\
\text { mean } \\
0.0625\end{array}$ & $\begin{array}{c}25^{\text {th }} \\
\text { \%ile } \\
-0.0005\end{array}$ & $\begin{array}{c}\text { Median } \\
0.0781\end{array}$ & $\begin{array}{c}75^{\text {th }} \\
\% \text { ile } \\
0.1281\end{array}$ & $\begin{array}{l}\text { Equity } \\
0.1109\end{array}$ & $\begin{array}{c}\text { 10-year } \\
\text { Treasuries } \\
0.0375\end{array}$ & $\begin{array}{c}\text { Balanced } \\
\text { portfolio } \\
0.0815\end{array}$ & $\begin{array}{l}\text { Mean } \\
-0.0218\end{array}$ & $\begin{array}{l}\text { Weighted } \\
\text { mean } \\
-0.0139\end{array}$ & $\begin{array}{l}\text { Median } \\
-0.0177\end{array}$ \\
\hline $\begin{array}{l}\text { Medium: } \\
\$ 100 \mathrm{~mm}>\text { assets }>\$ 10 \mathrm{~mm}\end{array}$ & 34,236 & 0.0565 & 0.0534 & 0.0000 & 0.0618 & 0.1179 & 0.1165 & 0.0359 & 0.0842 & -0.0277 & -0.0264 & -0.0251 \\
\hline $\begin{array}{l}\text { Small: } \\
\$ 10 \mathrm{~mm}>\text { assets }>\$ 1 \mathrm{~mm}\end{array}$ & 88,088 & 0.0507 & 0.0490 & 0.0000 & 0.0419 & 0.1026 & 0.1215 & 0.0343 & 0.0866 & -0.0359 & -0.0331 & -0.0327 \\
\hline $\begin{array}{l}\text { Tiny: } \\
\text { Assets }<\$ 1 \mathrm{~mm}\end{array}$ & 135,635 & 0.0364 & 0.0387 & 0.0000 & 0.0077 & 0.0757 & 0.1230 & 0.0330 & 0.0870 & -0.0506 & -0.0444 & -0.0483 \\
\hline Full Sample & 265,548 & 0.0444 & 0.0601 & 0.0000 & 0.0257 & 0.0955 & 0.1213 & 0.0339 & 0.0864 & -0.0420 & -0.0172 & -0.0392 \\
\hline
\end{tabular}




\section{Table 4}

\section{Abnormal net investment returns}

The table shows regression estimates of investment alphas for a sample of U.S. non-profit organizations between 2009-2018 for which we have at least seven years of annual data. The analysis is limited to 24,235 endowment funds that report at least seven years of performance data in U.S. Internal Revenue Service Form 990 filings. We fit a separate time series regression for each endowment fund, and report the cross-sectional average of these alpha estimates and the bootstrapped $p$-values of estimated alphas, calculated according to a method described more fully in the text. The remaining rows report estimates from the four-factor model that includes the Vanguard Total Stock Market Index ETF (VTI), Vanguard FTSE All-World ex-US ETF (VEU), iShares Core U.S. Aggregate Bond ETF (AGG), and the Hedge Fund Research Index (HFRI). For the last four columns each endowment is assigned to one of the four size cohorts based on its average start-of-year assets. The full model is:

$$
\left(R_{i, t}-R_{f, t}\right)=\alpha_{i}+\beta_{i, V T I}\left(R_{V T I, t}-R_{f, t}\right)+\beta_{i, V E U}\left(R_{V E U, t}-R_{f, t}\right)+\beta_{i, A G G}\left(R_{A G G, t}-R_{f, t}\right)+\beta_{i, H F R I}\left(R_{H F R I, t}-R_{f, t}\right)+\varepsilon_{i, t}
$$

\begin{tabular}{|c|c|c|c|c|c|}
\hline & $\begin{array}{c}\text { Entire } \\
\text { Sample }\end{array}$ & $\begin{array}{c}\text { Large: } \\
\text { assets > } \\
\$ 100 \mathrm{~mm}\end{array}$ & $\begin{array}{c}\text { Medium: } \\
\$ 10 \mathrm{~mm}< \\
\text { assets < } \\
\$ 100 \mathrm{~mm}\end{array}$ & $\begin{array}{c}\text { Small: } \\
\$ 1 \mathrm{~mm}< \\
\text { assets < } \\
\$ 10 \mathrm{~mm}\end{array}$ & $\begin{array}{c}\text { Tiny: } \\
\text { assets < } \\
\$ 1 \mathrm{~mm}\end{array}$ \\
\hline Alpha (cross-sectional average) & -0.0039 & -0.0093 & -0.0061 & -0.0036 & -0.0032 \\
\hline Cross-sectionally bootstrapped p-value & $<0.01$ & $<0.01$ & $<0.01$ & $<0.01$ & $<0.01$ \\
\hline Fraction of endowments with estimated alpha $<0$ & 0.63 & 0.67 & 0.63 & 0.60 & 0.64 \\
\hline Observations & 24,235 & 755 & 3,402 & 8,496 & 11,582 \\
\hline Fraction of observations & 1.000 & 0.031 & 0.140 & 0.351 & 0.478 \\
\hline Fraction of endowment assets & 1.000 & 0.775 & 0.171 & 0.049 & 0.006 \\
\hline$\beta_{V T I}$ (cross-sectional average) & 0.2469 & 0.3549 & 0.3080 & 0.2840 & 0.1946 \\
\hline$\beta_{V E U}$ (cross-sectional average) & 0.1253 & 0.1361 & 0.1642 & 0.1323 & 0.1081 \\
\hline$\beta_{A G G}$ (cross-sectional average) & 0.2103 & 0.2607 & 0.2616 & 0.2174 & 0.1868 \\
\hline$\beta_{\text {HFRI }}$ (cross-sectional average) & 0.0398 & 0.2190 & 0.1124 & 0.0292 & 0.0145 \\
\hline$R^{2}$ (cross-sectional average) & 0.7925 & 0.9333 & 0.8894 & 0.8129 & 0.7400 \\
\hline
\end{tabular}


Table 5

Abnormal net investment returns for higher education endowments

The table shows regression estimates of investment alphas for a sample of U.S. non-profit organizations between 2009-2018 for which we have at least seven years of annual data. The analysis is limited to 24,235 endowment funds that report at least seven years of performance data in U.S. Internal Revenue Service Form 990 filings. The subsample of the Top 50 Universities is based on 2021 rankings from U.S. News and World Report. This list includes 52 National Universities due to a four-way tie for the $49^{\text {th }}$ spot.

University of Michigan is excluded as it does not file form 990, leaving us with 51 schools. We fit a separate time series regression for each endowment fund, and report the cross-sectional average of these alpha estimates and the bootstrapped $p$-values of estimated alphas, calculated according to a method described more fully in the text. The remaining rows report estimates from the four-factor model that includes the Vanguard Total Stock Market Index ETF (VTI), Vanguard FTSE All-World ex-US ETF (VEU), iShares Core U.S. Aggregate Bond ETF (AGG), and the Hedge Fund Research Index (HFRI). For the last four columns each endowment is assigned to one of the four size cohorts based on its average start-of-year assets. The full model is:

$\left(R_{i, t}-R_{f, t}\right)=\alpha_{i}+\beta_{i, V I I}\left(R_{V T I, t}-R_{f, t}\right)+\beta_{i, V E U}\left(R_{V E U, t}-R_{f, t}\right)+\beta_{i, A G G}\left(R_{A G G, t}-R_{f, t}\right)+\beta_{i, H F R I}\left(R_{H F R I, t}-R_{f, t}\right)+\varepsilon_{i, t}$

\begin{tabular}{|c|c|c|c|c|c|c|}
\hline & $\begin{array}{c}\text { Entire } \\
\text { sample }\end{array}$ & $\begin{array}{c}\text { Colleges } \\
\text { and } \\
\text { universities }\end{array}$ & $\begin{array}{c}\text { All other } \\
\text { organizations }\end{array}$ & $\begin{array}{c}\text { Top } 50 \\
\text { universities }\end{array}$ & $\begin{array}{l}\text { NACUBO } \\
\text { reporting } \\
\text { funds }\end{array}$ & $\begin{array}{c}\text { Higher } \\
\text { education, } \\
\text { non- } \\
\text { NACUBO }\end{array}$ \\
\hline Alpha (cross-sectional average) & -0.0039 & -0.0064 & -0.0038 & -0.0206 & -0.0113 & -0.0006 \\
\hline Cross-sectionally bootstrapped $p$-value & $<0.01$ & $<0.01$ & $<0.01$ & $<0.01$ & $<0.01$ & $<0.50$ \\
\hline Fraction of endowments with estimated alpha $<0$ & 0.63 & 0.64 & 0.63 & 0.78 & 0.71 & 0.55 \\
\hline Observations & 24,235 & 1,217 & 23,018 & 51 & 909 & 609 \\
\hline$\beta_{V T I}$ (cross-sectional average) & 0.2469 & 0.3052 & 0.2438 & 0.5773 & 0.3621 & 0.2222 \\
\hline$\beta_{V E U}$ (cross-sectional average) & 0.1253 & 0.1158 & 0.1258 & 0.0397 & 0.1468 & 0.0940 \\
\hline$\beta_{A G G}$ (cross-sectional average) & 0.2103 & 0.2464 & 0.2084 & 0.1394 & 0.2776 & 0.2104 \\
\hline$\beta_{\text {HFRI }}$ (cross-sectional average) & 0.0398 & 0.1800 & 0.0324 & 0.1555 & 0.1964 & 0.1508 \\
\hline$R^{2}$ (cross-sectional average) & 0.7925 & 0.8812 & 0.7878 & 0.9469 & 0.9364 & 0.8149 \\
\hline
\end{tabular}




\section{Table 6}

\section{Distribution rates for endowments of different sizes}

The table shows descriptive statistics about the annual distribution rates for endowment funds, for a sample of 35,755 U.S. non-profit organizations between 2009-2018. Data are obtained from Internal Revenue Service Form 990 filings on Schedule D, Part V. The distribution rate is calculated as the ratio of distributions for grants and scholarships (Line 1d) plus distributions for facilities and programs (Line 1e) over the sum of beginning-of-year assets (Line 1a) plus 50\% of new contributions and transfers during the year (Line 1b).

$\begin{array}{ccccc}\text { Entire } & \text { Large: } & \text { Medium: } & \text { Small: } & \text { Tiny: } \\ \text { Sample } & \text { assets }> & \$ 10 \mathrm{~mm}< & \$ 1 \mathrm{~mm}< & \text { assets }< \\ & \$ 100 \mathrm{~mm} & \text { assets }< & \text { assets }< & \$ 1 \mathrm{~mm} \\ & & \$ 100 \mathrm{~mm} & \$ 10 \mathrm{~mm} & \end{array}$

Observations

Fraction of with zero distribution

Median distribution rate

Mean distribution rate

265,548
0.406
$1.73 \%$
$5.88 \%$

7,589

0.044

$4.35 \%$

$4.87 \%$
88,088

0.288

$2.97 \%$

$5.64 \%$
135,635

0.574

$0.00 \%$

$6.28 \%$ 


\section{Table 7}

\section{Distributions by endowments as a function of other sources of cash}

The table shows least squares regression estimates of the amounts of cash distributed from nonprofit endowment funds, as a function of six potential sources of cash for the parent organization. The cash distribution equals the sum of grants or scholarships (Line 1d) and other expenditures for facilities and programs (Line 1e) as reported in part V of Schedule D of Form 990. Cash donations equal the sum of federated campaigns (Part VIII, Line 1a), fundraising events (Part VIII, Line 1c) and other gifts (Part VIII, Line 1f). Operating surplus equals program service revenue (Part VII, Line 2g) minus program service expenses (Part IX, Line 25). Endowment earnings is from Part $\mathrm{V}$ of Schedule $\mathrm{D}$ (Line 1b). Net change in long-term debt equals the difference in bonds, loans, and notes outstanding at the end of year from the beginning of the year (sum of Line 20, Line 23, and Line 24 in Part X). Government grants received equal cash from newly awarded grants (Part VIII, Line 1e) minus changes in grants and pledges receivable (Part X, Line 3). Cash on the balance sheet is the sum of reported cash (Part X, Line 1) and savings (Part X, Line 2). All filings by "supporting public charities" are excluded. All models include endowment fixed effects and are estimated using the Stata areg procedure. Standard errors clustered at the organization level appear in parentheses.

$\begin{array}{lccccc} & \begin{array}{c}\text { Entire } \\ \text { Sample }\end{array} & \begin{array}{c}\text { Large: } \\ \text { assets }> \\ \$ 100 \mathrm{~mm}\end{array} & \begin{array}{c}\text { Medium: } \\ \$ 10 \mathrm{~mm}< \\ \text { assets }< \\ \$ 100 \mathrm{~mm}\end{array} & \begin{array}{c}\text { Small: } \\ \$ 1 \mathrm{~mm}< \\ \text { assets }< \\ \$ 10 \mathrm{~mm}\end{array} & \begin{array}{c}\text { Tiny: } \\ \text { assets }< \\ \$ 1 \mathrm{~mm}\end{array} \\ \text { Cash donations } & 0.0234 & 0.0627 & 0.0061 & -0.0015 & 0.0006 \\ & (0.0255) & (0.0423) & (0.0046) & (0.0010) & (0.0006) \\ \text { Operating surplus } & -0.0408^{* *} & -0.0886^{* *} & 0.0010 & -0.0026^{*} & -0.0000 \\ & (0.0205) & (0.0420) & (0.0023) & (0.0013) & (0.0002) \\ \text { Endowment earnings } & -0.0079 & -0.0096 & 0.0196^{* *} & 0.0758^{* * *} & 0.0320 \\ & (0.0205) & (0.0197) & (0.0099) & (0.0247) & (0.0228) \\ \text { Net change in long term debt } & 0.0024 & 0.0021 & -0.0012 & 0.0001 & 0.0001 \\ & (0.0091) & (0.0188) & (0.0016) & (0.0003) & (0.0001) \\ \text { Government grants received } & 0.0032 & 0.0128 & -0.0038 & 0.0038 & -0.0001 \\ & (0.0306) & (0.0424) & (0.0069) & (0.0027) & (0.0003) \\ \text { Cash on balance sheet } & 0.0186 & 0.0325 & -0.0025 & 0.0007 & 0.0000 \\ & (0.0185) & (0.0235) & (0.0036) & (0.0006) & (0.0001) \\ \text { Observations } & 159,840 & 4,875 & 19,713 & 50,350 & 84,902 \\ R^{2} & 0.9616 & 0.9609 & 0.8227 & 0.4626 & 0.7033\end{array}$

Significant at $1 \%(* * *), 5 \%(* *)$ and $10 \%(*)$ levels. 


\section{Table 8}

Investment returns and subsequent donations to parent organization

The table shows regression estimates for a model of the growth in donations to the parent organizations of endowment funds, for a sample of 35,184 U.S. non-profit organizations between 2009-2018. The dependent variable is the log of the ratio of current year donations over prior year donations. Donations are estimated based on data reported in Part VIII of the Form 990 filing. Total donations equal the sum of Line 1a (federated campaigns), Line 1c (fund raising events), and Line 1f (all other contributions) of Part VIII. The main explanatory variable is the lagged endowment return compounded continuously. In the second and third columns we include the continuously compounded returns on the CRSP value weighted equity market index, and the 60-40 combination of the equity market index and the CRSP 10-Year U.S. Treasury bond index. All models include endowment fixed effects and are estimated using the Stata areg procedure. Standard errors clustered at the organization level appear in parentheses.

Lagged endowment return

Lagged equity market return

Lagged 60-40 balanced portfolio return

Observations

$R^{2}$

Significant at $1 \%(* * *), 5 \%(* *)$ and $10 \%(*)$ levels.

$\begin{array}{ccc}\text { Estimate } & \text { Estimate } & \text { Estimate } \\ 0.2146^{* * *} & 0.0692 & 0.1104^{* *} \\ (0.0413) & (0.0594) & (0.0555)\end{array}$

$0.1512^{* * *}$

$0.2295^{* * *}$

(0.0744)

$149,857 \quad 149,857$

$0.1308 \quad 0.1309$ 


\section{Figure 1}

The figure shows differences in annual investment returns for endowment fund averages minus the a benchmark portfolio comprised of $60 \%$ of the CRSP value-weighted equity index and $40 \%$ of the CRSP ten-year U.S. Treasury bond index Each bar represents a cohort of funds with fiscal years ending in a particular month, with the first bar representing funds whose fiscal years end in January 2009 and the final bar representing funds whose reporting periods end in December 2018. The top panel shows performance for an equal-weighted average of all endowments, while the bottom panel shows performance for a size-weighted average. The sample includes 35,755 U.S. non-profit organizations between 2009-2018. Endowment data are obtained from Part V of Schedule D of these organizations' Internal Revenue Service Form 990 filings. Detail about sample sizes and returns for each reporting period appears in appendix Table A3.

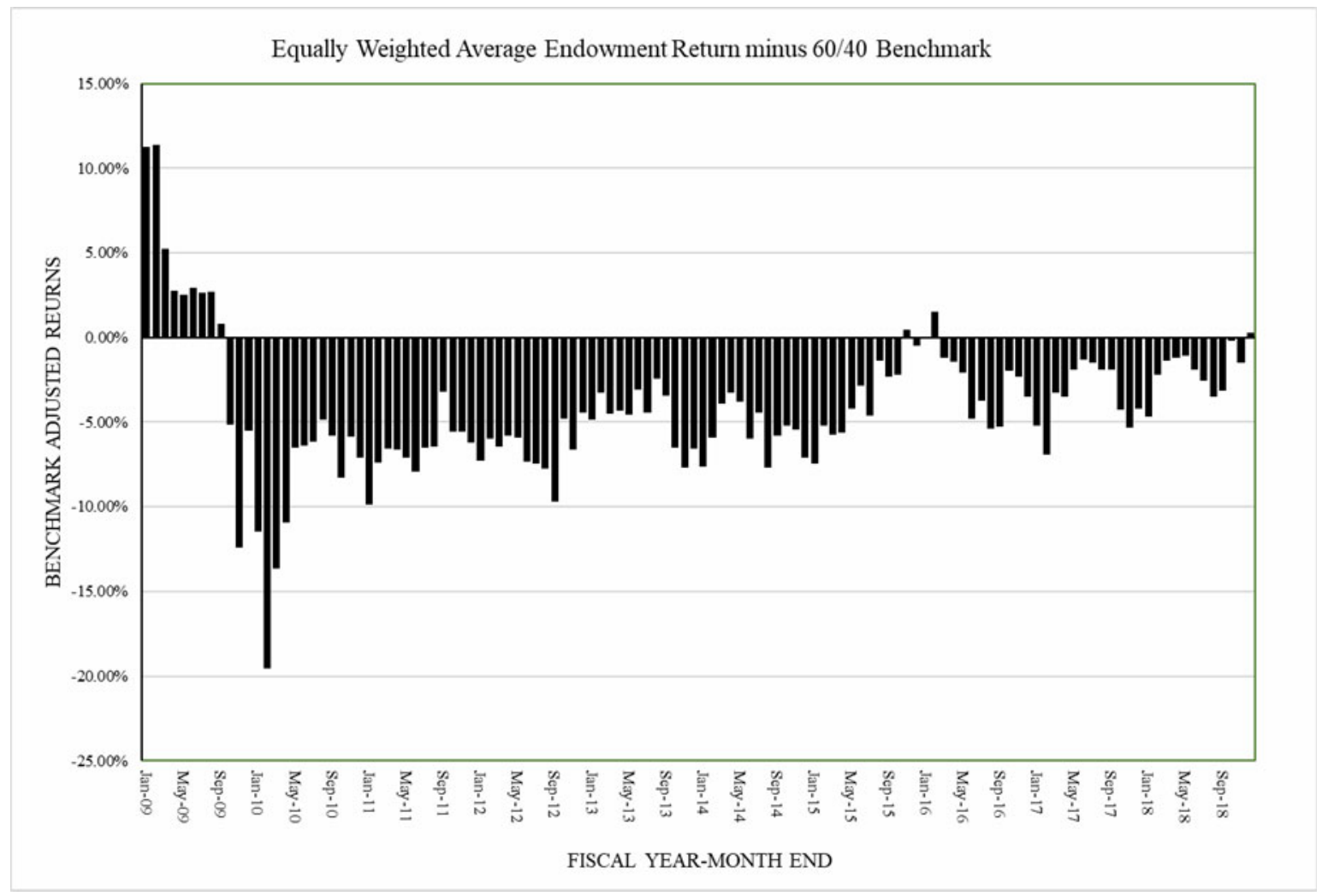




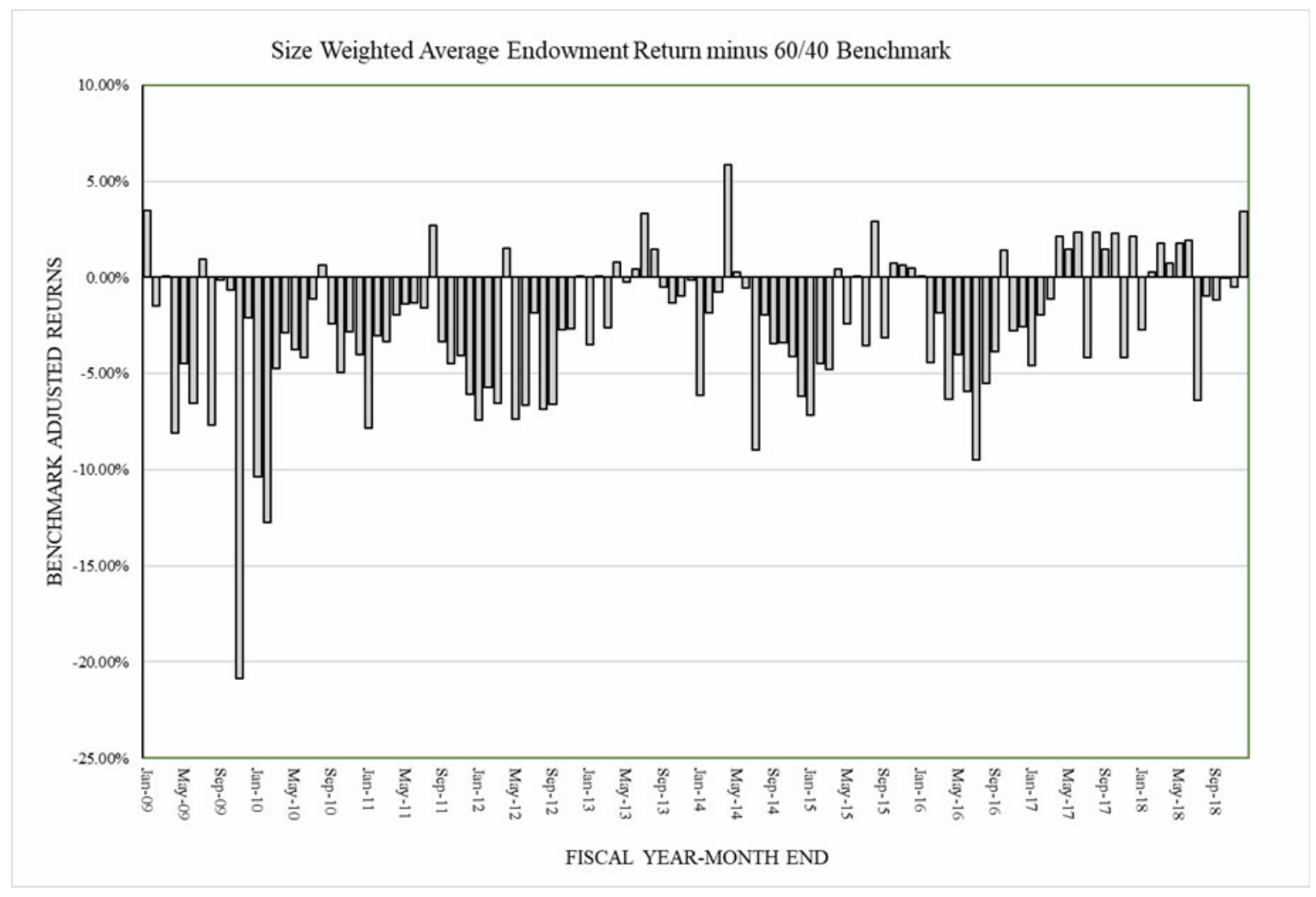




\section{Appendix 1 \\ Sample design}

We extract the data for our study from a publicly available sample of Form 990 filings used by non-profit organizations to report annual financial data to the U.S. Internal Revenue Service (IRS). Non-profits, those organizations claiming income tax exemptions under one of the 27 sub-sections of Section 501(c) of the federal tax code, must file either Form 990, Form 990-EZ, Form 990-PF (private foundations) or Form 990-N (e-Postcard) each year. A transition from paper to electronic filing began in 2010, leading to the compilation of large amounts of non-profit data in standardized, machine readable formats. However, the IRS did not make this data publicly available in an accessible way until a January 30, 2015 ruling issued by a federal judge in a lawsuit filed by open-records activist Carl Malamud.

Starting from June 15, 2016 the IRS has published Form 990 filings in a machinereadable, cloud-based format on Amazon Web Services (AWS), where it may be accessed by researchers at https://registry.opendata.aws/irs990/. Data for each Form 990 filing is provided in an XML file that contains structured information representing the main form, any filed forms and schedules, and other control information. The available data includes Forms 990, 990-EZ and 990-PF but not Form 990-N (e-Postcard), and it is updated periodically with information from new filings.

AWS provides different "index files” on a calendar year basis in JSON and CSV formats. For example, the CSV index for 2013 is available at https://s3.amazonaws.com/irs-form-990/index_2013.csv, and the JSON index file for 2015 is available at https://s3.amazonaws.com/irs-form-990/index_2015.json. Since 
these index files are based on filing dates rather than the fiscal year-end dates of each organization, it is common for filings to appear in a particular calendar year index file that cover earlier fiscal years. Each index file allows us to separate Form 990 filings from others and includes an URL address for each individual filing's corresponding XML file. We use these URL addresses to locate and harvest the Form 990 XML data. ${ }^{24}$

Our main source of endowment data is Part V of Schedule D of Form 990. Figure A1 provides an illustrative example of the 2012 filing for New York University, covering the fiscal year from September 1, 2011 through August 31, 2012. This table consists of seven line items which are self-explanatory. More detailed description is provided in an IRS publication titled "Instructions for Schedule D (Form 990)" available at https://www.irs.gov/pub/irs-pdf/i990sd.pdf.

For our study covering the period 2009-2018, we have downloaded Form 990 data from AWS several times when preparing successive drafts of this paper. Most recently we obtain data on January 9, 2021, which provides a sample universe of 1,909,645 annual Form 990 filings representing fiscal years since 2010. As we describe more fully later, the filings allow us to backfill endowment related data for 2009. Data in Table A1 imply that about 250,000 organizations currently file Form 990 electronically each fiscal year, and delays in filing and lags in IRS processing may lead to several years of elapsed time before a virtually complete cohort of returns is available on AWS for a given fiscal year. The table also implies that as of January 2021, the AWS data currently

\footnotetext{
${ }^{24}$ One filing by Dream Builders Mission, EIN 81-1338606, has an electronic filing available at https://s3.amazonaws.com/irs-form-990/201940149349301304_public.xml with an improper XML schema. This filer does not have an endowment, and we exclude it from our sample like other such organizations.
} 
contains about one-half of the observations that will eventually be filed for the 2019 fiscal year, and some early filings for fiscal 2020 as well.

We go through a number of screens to reduce the 1.9 million Form 990 filings to the sample used in our study. Table A2 describes the process step-by-step.

\section{Drop duplicate filings}

We begin by eliminating duplicate filings. There are 1,291 filings that are complete duplicates, and we drop these. This reduces the sample size to 1,908,354. An additional 13,969 filings are duplicates in terms of employer identification number (EIN) and year but have different timestamps. We retain the latest timestamped filings. Dropping these 13,969 duplicate filings results in a sample of 1,894,385 unique EIN-year observations for 337,786 organizations.

\section{Add imputed interior observations}

Next we take advantage of the structure of endowment data reported in Part V of Schedule D of Form 990. The table asks organizations to provide endowment data for the reporting year as well as up to four years of lagged historical values. We identify organizations whose sequences of filings are interrupted by at least one missing "interior" year that falls between a start year and an end year in which electronic filings occur (an organization may have reverted to paper filings in the missing years). There are 97,223 such cases, and we are able to use lagged historical data from later filings to fill in the data for 93,802 of them, or more than $96 \%$. Note that we retain even blank or zero data at this point, as zero-valued endowments will be dropped from the sample in the next step described below. We add back these 93,802 “imputed” missing interior years, increasing our sample size to 1,988,187 observations. 


\section{Drop observations without endowments}

We drop observations for EIN-years during which organizations give no indication of having endowment funds. Endowment data are reported in a table in Part V of Schedule D of Form 990, and we identify 1,744,846 filings (nearly $88 \%$ of the potential sample) where each of the seven line items are left blank or where this schedule is omitted. Basic financial data indicate that these non-endowment observations are overwhelmingly associated with smaller non-profits. ${ }^{25}$ After excluding all filings for which endowment data is not reported, our sample size becomes 243,341.

\section{Drop observations with problematic or missing data}

We next identify endowment observations with problematic data. Our calculations require useable data for endowment balances at the beginning of the year (Line 1a) and end of the year (Line 1g). We flag all observations where beginning or ending balances are either missing or reported as less than or equal to zero For these observations we check filings up to four years in the future to see if the data is later corrected. After these repairs, we drop the 6,377 observations that we cannot correct, reducing the sample to 236,964.

\section{Drop observations with irregular fiscal years}

A small number of observations have irregular reporting periods, often due to transition periods associated with changes in fiscal year-end dates. If the number of days

\footnotetext{
${ }^{25}$ We obtain financial data from other parts of Form 990 to compare those non-profits with endowments against the much larger group of those without endowments. There are 243,341 observations with valid financial data in the former group, and 1,744,846 observations in the latter group. The total revenue of the endowment group has a mean of $\$ 37.1$ million, compared to a mean of $\$ 6.8$ million for the non-endowment group. Total assets for the endowment group are $\$ 82.4$ million on average (including the endowments themselves), compared to $\$ 13.7$ million for the non-endowment group. Total reported compensation for the two groups is $\$ 16.2$ million vs. $\$ 2.1$ million. All of these differences in means are statistically significant even at very low levels.
} 
in the reported fiscal year is less than 360 or greater than 370, we drop those filings, a total of 134 observations, reducing the sample to 236,830.

\section{Drop observations for organizations sharing the same endowment}

In 1,240 cases two or more organizations report exactly the same endowment data

in at least one year while reporting different balance sheet or operating data on Form 990. These organizations fall into two broad groups. In some cases two different operating entities are allied with the same endowment fund. ${ }^{26}$ The alternative variation occurs when a separate legal entity holds the endowment in the form of a foundation that supports an operating entity, but both report the endowment on their Form 990 filings. ${ }^{27}$ In these situations, we wish to avoid having more than one observation for each endowment-year so that identical observations are not repeated in our sample. We attempt to identify the senior or "parent" organization by looking at the total revenue reported each year on Form 990. This method resolves almost all of the cases and in a few dozen ambiguous cases we identify the more junior organization by choosing randomly. For the 1,240 junior organizations we drop all annual filings, eliminating a total of 8,437 observations. This adjustment reduces the sample size to 228,393.

\footnotetext{
${ }^{26}$ For example, Dana-Farber Inc. (EIN 04-3102433) and Dana-Farber Cancer Institute Inc. (EIN 042263040) are obviously related and report exactly same data for Part V of Schedule D, but no other part of their Forms 990 is the same.

${ }^{27}$ For example, Concordia University Wisconsin (EIN 39-0833608) and Concordia University Wisconsin Foundation Inc. (EIN 39-6077337). In some cases the names of the two entities does not suggest an obvious connection. For example, Indiana State University Foundation Inc. (EIN 35-6045550) and Sycamore Foundation Holdings Inc. (EIN 26-3673809) report exactly same Part V data but differ on everything else. After further research one finds that the stated mission of Sycamore Foundation Holdings Inc. is to provide support to Indiana State University Foundation, Inc., including soliciting and receiving charitable contributions and managing real property and other investments (the university’s sports teams are nicknamed the Sycamores). Unlike private universities, public universities do not file Form 990. However, many public universities house their endowments in legally separate foundations such as Indiana State University Foundation, Inc., which do file Form 990 and are therefore included in our sample.
} 


\section{Add lagged historical observations when available}

The Schedule D, Part V endowment table reports data for up to four prior years. We locate the first annual filing for each organization in the sample, and based upon the completeness of the disclosure in this filing, we add observations of endowment data (but no other data) for up to four prior years. We apply the same missing/unusual data screens described above to this backfilled data. This yields an additional 61,366 observations, increasing the sample size to 289,759.

\section{Drop observations with inconsistent data}

The Schedule D, Part V endowment table has seven line items which must be related to each other through the following identity:

$$
\begin{aligned}
\text { End-of-year balance (Line 1g) } & =\text { Start-of-year balance (Line 1a) } \\
& + \text { Contributions (Line 1b) } \\
& \pm \text { Investment Gain/loss (Line 1c) } \\
& - \text { Grants (Line 1d) } \\
& - \text { Other Expenses (Line 1e) } \\
& - \text { Administrative Expenses (Line 1f) }
\end{aligned}
$$

We check the internal consistency of each observation according to this identity. Some observations require adjustments for sign conventions, as they report the outflow lines $1 \mathrm{~d}$, 1e, and $1 \mathrm{f}$ as negative numbers while a vast majority report these line items as positive numbers. We take the absolute value of the reported entry for each of these three line items. After this adjustment, for 278,222 out of 289,759 observations (about $96 \%$ of the sample) the endowment identity holds exactly.

For the remaining 11,537 observations that exhibit some discrepancy in the identity, we check future filings by the same organization to see if corrected data is 
reported that resolves the issue. This method proves successful by using data from the next year's filing in 1,428 cases. For a further 495 observations we resolve the issue by looking at filings two years ahead, and we find corrections for 302 observations in filings three years ahead, and for 250 observations in filings four years ahead. We use this corrected, consistent data in place of the original inconsistent data, leaving 9,062 observations still with discrepancies.

For this last group, we check whether the size of discrepancy in the endowment identity is de minimus, which we define as less than $1 \%$ of the sum of start-of-year assets plus one half of contributions. This tolerance is satisfied by 5,011 observations, and we retain these, leaving 4,051 observations with larger discrepancies which we drop. This reduces the sample size to 285,708 observations.

\section{Drop observations out of sample range}

We drop 4,707 observations for fiscal years ending in 2008 and a further 14,899 observations for fiscal years ending in 2019 or 2020. These exclusions reduce our sample size to 266,102 observations.

\section{Drop observations with extreme distribution data}

We estimate the annual endowment return as:

Endowment Return $=\frac{[(\text { Investment Gain } / \text { Loss })-(\text { Admin Expenses })]}{[(\text { BoY Assets })+0.5 \times(\text { Contributions })-0.5 \times(\text { Grants }+ \text { Other Expenses })]}$

For 22 observations, the outflow variables of Grants and Other Expenses are large enough to make the denominator negative, which will mechanically make the endowment return negative even if the endowment has a positive net investment gain. We drop these 22 observations as we are not able to estimate reliably the annual investment return. 
This reduces our sample to 266,080.

\section{Trim top and bottom $0.1 \%$ of observations}

Since the endowment return calculation is a ratio, a small denominator can create large outliers. We address this issue by dropping those observations which have an endowment return in the lowest $0.1 \%$ (266 observations) and in the largest $0.1 \%$ (266 observations). Roughly speaking, we are deleting those observations with negative annual returns of $-58 \%$ or lower, and with positive annual returns of $+82 \%$ or higher. This results in final sample of 265,548 observations.

The 532 outliers that we trim are almost evenly distributed across the ten years of the sample, with every year having at least 42 of these trimmed observations, and no year having more than 62 . They follow an industry pattern very similar to the overall sample. The 532 outliers are disproportionately concentrated among smaller endowments. Only five of the 532 outliers, or $0.9 \%$, occur in endowments with asset values exceeding $\$ 100$ million, while 379 of the outliers, or $71.2 \%$, occur in endowments with asset values below $\$ 1$ million. In untabulated results we find that trimming these observations has only a very minor impact on our alpha estimates. However, some of the outliers are so severe that failing to trim them significantly impacts descriptive statistics such as the mean (but not median) and standard deviation. For instance, the standard deviation of the overall sample returns, which is reported as $8.3 \%$ in Table 2 , would be $89.7 \%$ if the $0.2 \%$ of outlier observations were not trimmed and instead retained their pathologically large values. 


\section{Figure A1}

Form 990, Section D, Part V filing for New York University for fiscal year ended August 31, 2012

This example shows the seven line items disclosed by non-profit organizations about their endowments in annual IRS filings since 2010. The calendar year in which the final month of the fiscal year reporting period occurs determines the placement of each observation in our sample, so in this example, the "current year" in column (a) would be classified as a 2012 observation since the fiscal year ends in August 2012. The prior years in column (b), (c), and (d) would represent data for the years 2011, 2010, and 2009 in our sample. Even though disclosure of this information did not begin until 2010, we obtain data for 2009 for this organization and many others by using the lagged historical data reported in this table. Note that the organization has left blank column (e), as the IRS did not require historical disclosure for 2008 and earlier years.

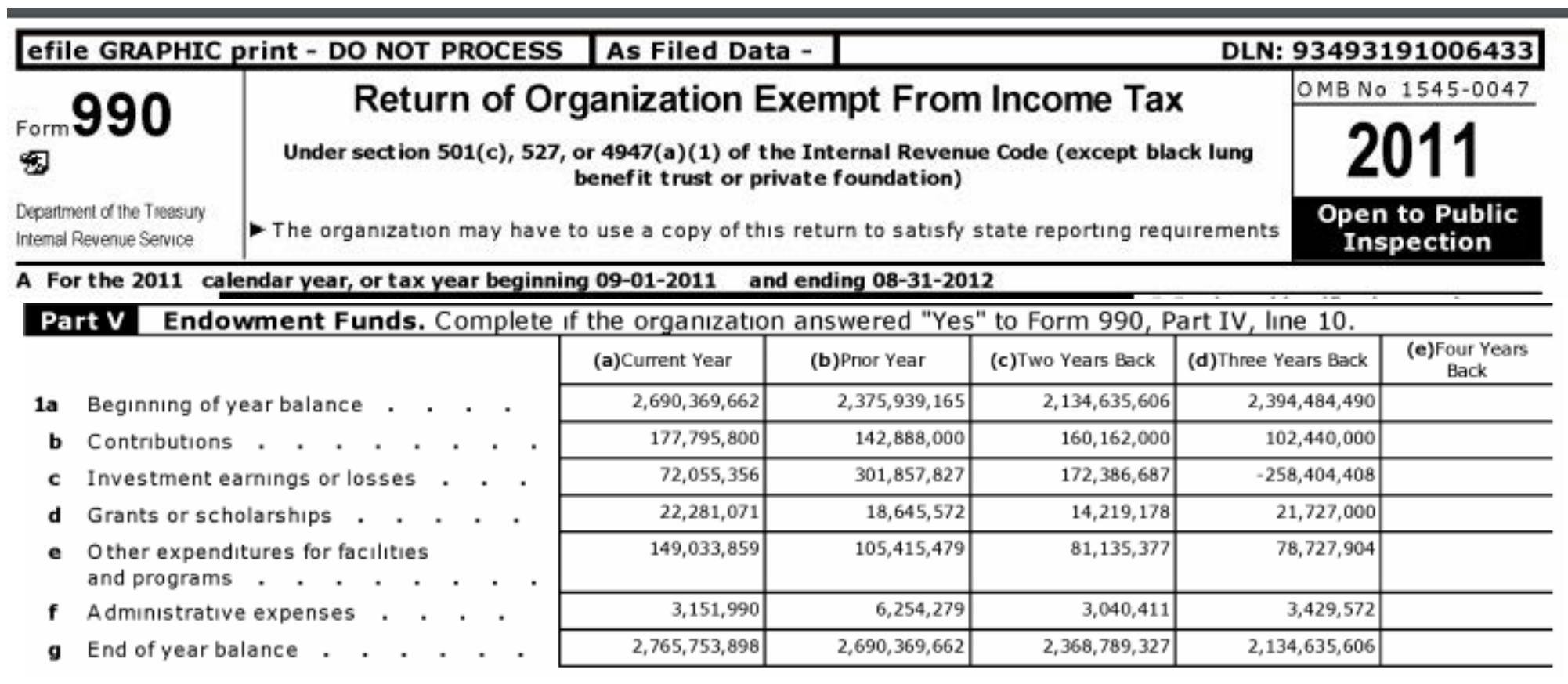


Table A1

Distribution of AWS filings by fiscal year, as of June 2020

\begin{tabular}{|c|c|c|c|}
\hline $\begin{array}{c}\text { Fiscal } \\
\text { year } \\
\text { end }\end{array}$ & Observations & $\begin{array}{c}\text { Annual } \\
\text { percentage }\end{array}$ & $\begin{array}{l}\text { Cumulative } \\
\text { percentage }\end{array}$ \\
\hline 2010 & 98,206 & $5.14 \%$ & $5.14 \%$ \\
\hline 2011 & 139,341 & $7.30 \%$ & $12.44 \%$ \\
\hline 2012 & 170,760 & $8.94 \%$ & $21.38 \%$ \\
\hline 2013 & 190,513 & $9.98 \%$ & $31.36 \%$ \\
\hline 2014 & 210,515 & $11.02 \%$ & $42.38 \%$ \\
\hline 2015 & 228,000 & $11.94 \%$ & $54.32 \%$ \\
\hline 2016 & 240,291 & $12.58 \%$ & $66.90 \%$ \\
\hline 2017 & 251,181 & $13.15 \%$ & $80.05 \%$ \\
\hline 2018 & 250,542 & $13.12 \%$ & $93.17 \%$ \\
\hline 2019 & 126,735 & $6.64 \%$ & $99.81 \%$ \\
\hline 2020 & 3,561 & $0.19 \%$ & $100.00 \%$ \\
\hline Total & $1,909,645$ & $100.00 \%$ & \\
\hline
\end{tabular}




\section{Table A2}

\section{Sample selection process}

Universe of all form 990 "Electronic" filings as of January 2021

$1,909,645$

Remove complete duplicates

$(1,291)$

Remove duplicates in terms of EIN and year, retaining latest time stamp

Unique EIN-year observations

$1,894,385$

Add missing interior-year data that is reported in subsequent years' filings

93,802

Remove observations reporting no endowment data

$1,988,187$

$(1,744,846)$

243,341

Remove observations with problematic data for endowment balances

$(6,377)$

236,964

(134)

Remove observations for fiscal years with irregular length

Remove organizations reporting at least one year of identical endowment

data as an affiliate organization that we retain

228,393

Add backfilled annual data from first disclosure for each organization

61,366

289,759

Remove observations not satisfying endowment identity within 1\%

$(4,051)$

$(4,707)$

Remove observations for 2008 fiscal year

$(14,899)$

Remove observations for 2019 and 2020 fiscal years

Remove observations with extreme distribution data

Final Sample

265,548 


\section{Appendix 2 \\ Endowment return data for each monthly fiscal year reporting period}

Table A3 provides month-by-month performance data for the endowment funds in our sample alongside the relevant equity and debt market benchmarks, in a format identical to Table 3. Each row of the table shows the sample size and summary statistics for endowment returns for those funds whose 12-month fiscal year reporting periods end in that month. Specifically, for each calendar month we identify all endowments with their fiscal years ending in that month. We calculate the median and inter-quartile returns for these subsets of endowments and report these statistics in columns two through four. We next calculate the returns for the CRSP value weighted index and the CRSP 10-Year U.S. Treasury Bond index over the same 12-month periods that match the fiscal years of the endowments. As shown in the table, a significant number of endowments have fiscal years ending in either June or December, with a smaller number ending in September and the rest scattered among the remaining nine months of each year. In addition, our sample size gradually increases over time, as more non-profit firms comply with electronic filing requirements phased in during our sample period by the IRS. 


\section{Table A3}

\section{Endowment returns}

The table shows summary statistics of net investment returns on endowment funds for a sample of 35,755 U.S. non-profit organizations between 2009-2018. Each line of the table shows the distribution of annual endowment returns and the comparable trailing 12-month benchmark returns for observations whose 12-month fiscal year reporting periods end in that month. Endowment data are obtained from Part V of Schedule D of Internal Revenue Service Form 990 filings. The annual net investment return for each endowment fund equals net endowment investment gains/losses (Line 1c) minus any administrative expenses (Line 1f), divided by start of year endowment assets plus 0.5 times endowment contributions (Line 1b) minus 0.5 times endowment distributions (Lines $1 \mathrm{~d}$ and 1e). Benchmark returns are based on the Center for Research in Securities Prices (CRSP) value-weighted index, the CRSP 10Year U.S. Treasury Bond Index, and a "balanced portfolio" comprised of $60 \%$ of the CRSP equity index and 40\% of the Treasury bond index. The weighted mean is calculated using start-of-year endowment assets (Line 1a) as the weighting factor within each size cohort as well as the full sample.

Fiscal

year-end month

2009m1

2009m2

2009m3

2009m4

2009m5

2009m6

2009m7

2009m8

2009m9

2009m10

2009m11

2009m12

2010m1

2010m2
Endowment returns

$\begin{array}{cc}\begin{array}{c}\text { Weighted } \\ \text { mean }\end{array} & \begin{array}{c}25^{\text {th }} \\ \% l e\end{array} \\ -0.1674 & -0.2100 \\ -0.2509 & -0.2706 \\ -0.1936 & -0.2608 \\ -0.2631 & -0.2527 \\ -0.2093 & -0.2292 \\ -0.2004 & -0.1837 \\ -0.0818 & -0.1274 \\ -0.1601 & -0.1116 \\ -0.0029 & -0.0092 \\ 0.1124 & 0.0024 \\ -0.0118 & 0.0000 \\ 0.1434 & 0.0005 \\ 0.1208 & 0.0000 \\ 0.2223 & 0.0000\end{array}$

Benchmark returns

Mean
-0.0896
-0.1222
-0.1415
-0.1550
-0.1394
-0.1052
-0.0647
-0.0566
0.0065
0.0673
0.0724
0.1094
0.1098
0.1541

Median
-0.0063
-0.1304
-0.1690
-0.1940
-0.1751
-0.1241
-0.0577
-0.0524
0.0000
0.0590
0.0080
0.1049
0.0838
0.1500

$75^{\text {th }}$

\%ile

0.0195

0.0000

0.0000

0.0000

$-0.0016$

0.0000

0.0000

0.0000

0.0249

0.1263

0.1525

0.1975

0.2076

0.2705

Equity
-0.3922
-0.4410
-0.3861
-0.3521
-0.3242
-0.2690
-0.1986
-0.1820
-0.0521
0.1300
0.3050
0.3130
0.3702
0.5759

Endowment returns less balanced portfolio

\begin{tabular}{ccccc} 
10-year & Balanced & \multicolumn{3}{c}{ Weighted } \\
Treasuries & portfolio & Mean & mean & Median \\
0.0828 & -0.2022 & 0.1125 & 0.0347 & 0.1959 \\
0.0708 & -0.2363 & 0.1141 & -0.0146 & 0.1059 \\
0.0938 & -0.1942 & 0.0526 & 0.0006 & 0.0252 \\
0.0722 & -0.1823 & 0.0273 & -0.0808 & -0.0117 \\
0.0748 & -0.1646 & 0.0253 & -0.0447 & -0.0105 \\
0.0664 & -0.1349 & 0.0297 & -0.0656 & 0.0108 \\
0.0697 & -0.0913 & 0.0265 & 0.0095 & 0.0335 \\
0.0642 & -0.0835 & 0.0269 & -0.0766 & 0.0311 \\
0.0743 & -0.0016 & 0.0081 & -0.0013 & 0.0016 \\
0.1019 & 0.1188 & -0.0515 & -0.0063 & -0.0598 \\
0.0345 & 0.1968 & -0.1244 & -0.2086 & -0.1888 \\
-0.0583 & 0.1645 & -0.0551 & -0.0211 & -0.0596 \\
0.0060 & 0.2245 & -0.1147 & -0.1038 & -0.1407 \\
0.0100 & 0.3495 & -0.1954 & -0.1273 & -0.1996
\end{tabular}




\begin{tabular}{|c|c|c|c|c|c|c|c|c|c|c|c|c|}
\hline 2010m3 & 432 & 0.1745 & 0.2639 & 0.0021 & 0.1756 & 0.3145 & 0.5424 & -0.0359 & 0.3111 & -0.1366 & -0.0471 & -0.1355 \\
\hline 2010m4 & 190 & 0.1482 & 0.2288 & 0.0104 & 0.1589 & 0.2517 & 0.4182 & 0.0164 & 0.2575 & -0.1093 & -0.0287 & -0.0985 \\
\hline 2010m5 & 602 & 0.0928 & 0.1200 & 0.0221 & 0.1083 & 0.1444 & 0.2231 & 0.0595 & 0.1576 & -0.0648 & -0.0376 & -0.0494 \\
\hline 2010m6 & 8,883 & 0.0716 & 0.0942 & 0.0063 & 0.0783 & 0.1177 & 0.1646 & 0.0923 & 0.1357 & -0.0641 & -0.0415 & -0.0574 \\
\hline 2010m7 & 295 & 0.0667 & 0.1167 & 0.0064 & 0.0659 & 0.1053 & 0.1523 & 0.0919 & 0.1281 & -0.0615 & -0.0114 & -0.0623 \\
\hline 2010m8 & 816 & 0.0408 & 0.0958 & 0.0012 & 0.0399 & 0.0686 & 0.0693 & 0.1194 & 0.0893 & -0.0485 & 0.0065 & -0.0494 \\
\hline 2010m9 & 1,659 & 0.0543 & 0.0884 & 0.0030 & 0.0561 & 0.0906 & 0.1167 & 0.1057 & 0.1123 & -0.0580 & -0.0239 & -0.0562 \\
\hline $2010 \mathrm{~m} 10$ & 147 & 0.0744 & 0.1082 & 0.0076 & 0.0782 & 0.1218 & 0.1930 & 0.1039 & 0.1574 & -0.0830 & -0.0492 & -0.0792 \\
\hline $2010 \mathrm{~m} 11$ & 38 & 0.0525 & 0.0828 & 0.0000 & 0.0360 & 0.0830 & 0.1344 & 0.0755 & 0.1108 & -0.0584 & -0.0280 & -0.0748 \\
\hline $2010 \mathrm{~m} 12$ & 9,422 & 0.0650 & 0.0961 & 0.0022 & 0.0679 & 0.1103 & 0.1771 & 0.0745 & 0.1361 & -0.0710 & -0.0400 & -0.0682 \\
\hline 2011m1 & 41 & 0.0697 & 0.0902 & 0.0015 & 0.0750 & 0.1190 & 0.2459 & 0.0523 & 0.1685 & -0.0988 & -0.0783 & -0.0935 \\
\hline 2011m2 & 74 & 0.0959 & 0.1396 & 0.0002 & 0.0703 & 0.1462 & 0.2500 & 0.0500 & 0.1700 & -0.0740 & -0.0303 & -0.0997 \\
\hline 2011m3 & 531 & 0.0678 & 0.0998 & 0.0057 & 0.0708 & 0.1136 & 0.1791 & 0.0644 & 0.1332 & -0.0655 & -0.0335 & -0.0624 \\
\hline 2011m4 & 245 & 0.0724 & 0.1189 & 0.0049 & 0.0848 & 0.1304 & 0.1891 & 0.0624 & 0.1384 & -0.0660 & -0.0195 & -0.0536 \\
\hline 2011m5 & 721 & 0.1170 & 0.1744 & 0.0248 & 0.1400 & 0.1834 & 0.2721 & 0.0620 & 0.1880 & -0.0711 & -0.0136 & -0.0481 \\
\hline 2011m6 & 10,538 & 0.1186 & 0.1842 & 0.0129 & 0.1390 & 0.1936 & 0.3154 & 0.0211 & 0.1977 & -0.0791 & -0.0135 & -0.0587 \\
\hline 2011m7 & 359 & 0.0733 & 0.1228 & 0.0077 & 0.0721 & 0.1295 & 0.2013 & 0.0446 & 0.1386 & -0.0653 & -0.0159 & -0.0666 \\
\hline 2011m8 & 959 & 0.0682 & 0.1592 & 0.0035 & 0.0698 & 0.1091 & 0.1829 & 0.0567 & 0.1324 & -0.0643 & 0.0268 & -0.0627 \\
\hline 2011m9 & 1,918 & -0.0012 & -0.0026 & -0.0173 & 0.0000 & 0.0092 & -0.0082 & 0.0899 & 0.0310 & -0.0322 & -0.0336 & -0.0310 \\
\hline $2011 \mathrm{~m} 10$ & 176 & 0.0158 & 0.0263 & 0.0000 & 0.0139 & 0.0353 & 0.0639 & 0.0824 & 0.0713 & -0.0555 & -0.0450 & -0.0574 \\
\hline $2011 \mathrm{~m} 11$ & 49 & 0.0157 & 0.0302 & 0.0000 & 0.0038 & 0.0367 & 0.0519 & 0.0997 & 0.0710 & -0.0554 & -0.0408 & -0.0672 \\
\hline $2011 \mathrm{~m} 12$ & 10,099 & -0.0024 & -0.0010 & -0.0199 & 0.0000 & 0.0085 & -0.0107 & 0.1660 & 0.0600 & -0.0624 & -0.0610 & -0.0600 \\
\hline 2012m1 & 41 & 0.0119 & 0.0103 & 0.0000 & 0.0032 & 0.0329 & 0.0232 & 0.1766 & 0.0846 & -0.0726 & -0.0742 & -0.0814 \\
\hline 2012m2 & 77 & 0.0217 & 0.0242 & 0.0000 & 0.0118 & 0.0386 & 0.0262 & 0.1643 & 0.0815 & -0.0597 & -0.0572 & -0.0696 \\
\hline 2012m3 & 568 & 0.0210 & 0.0199 & 0.0000 & 0.0132 & 0.0371 & 0.0474 & 0.1422 & 0.0853 & -0.0643 & -0.0655 & -0.0721 \\
\hline 2012m4 & 265 & 0.0119 & 0.0850 & -0.0058 & 0.0000 & 0.0208 & 0.0112 & 0.1578 & 0.0699 & -0.0580 & 0.0151 & -0.0699 \\
\hline 2012m5 & 749 & -0.0176 & -0.0323 & -0.0441 & -0.0171 & 0.0009 & -0.0408 & 0.1652 & 0.0416 & -0.0592 & -0.0740 & -0.0587 \\
\hline 2012m6 & 11,091 & 0.0013 & 0.0081 & -0.0142 & 0.0000 & 0.0132 & 0.0145 & 0.1644 & 0.0745 & -0.0732 & -0.0664 & -0.0745 \\
\hline 2012m7 & 393 & 0.0134 & 0.0694 & 0.0000 & 0.0066 & 0.0313 & 0.0486 & 0.1471 & 0.0880 & -0.0746 & -0.0186 & -0.0814 \\
\hline 2012m8 & 995 & 0.0448 & 0.0536 & 0.0014 & 0.0433 & 0.0744 & 0.1418 & 0.0924 & 0.1220 & -0.0772 & -0.0684 & -0.0787 \\
\hline 2012m9 & 1,995 & 0.0932 & 0.1242 & 0.0034 & 0.1040 & 0.1574 & 0.2808 & 0.0544 & 0.1902 & -0.0970 & -0.0660 & -0.0862 \\
\hline
\end{tabular}




\begin{tabular}{|c|c|c|c|c|c|c|c|c|c|c|c|c|}
\hline $2012 \mathrm{~m} 10$ & 192 & 0.0577 & 0.0784 & 0.0096 & 0.0591 & 0.0921 & 0.1335 & 0.0642 & 0.1058 & -0.0481 & -0.0274 & -0.0467 \\
\hline $2012 \mathrm{~m} 11$ & 53 & 0.0481 & 0.0880 & 0.0005 & 0.0467 & 0.0963 & 0.1476 & 0.0649 & 0.1145 & -0.0664 & -0.0265 & -0.0678 \\
\hline $2012 \mathrm{~m} 12$ & 10,643 & 0.0647 & 0.1095 & 0.0027 & 0.0704 & 0.1093 & 0.1577 & 0.0359 & 0.1090 & -0.0443 & 0.0005 & -0.0385 \\
\hline 2013m1 & 49 & 0.0508 & 0.0643 & 0.0012 & 0.0518 & 0.0847 & 0.1578 & 0.0115 & 0.0992 & -0.0484 & -0.0349 & -0.0474 \\
\hline 2013m2 & 79 & 0.0536 & 0.0873 & 0.0001 & 0.0413 & 0.0719 & 0.1212 & 0.0342 & 0.0864 & -0.0328 & 0.0009 & -0.0450 \\
\hline 2013m3 & 585 & 0.0588 & 0.0774 & 0.0057 & 0.0570 & 0.0875 & 0.1335 & 0.0587 & 0.1036 & -0.0448 & -0.0262 & -0.0466 \\
\hline 2013m4 & 289 & 0.0707 & 0.1220 & 0.0048 & 0.0755 & 0.1080 & 0.1584 & 0.0475 & 0.1140 & -0.0434 & 0.0080 & -0.0385 \\
\hline 2013m5 & 766 & 0.1057 & 0.1490 & 0.0291 & 0.1264 & 0.1602 & 0.2633 & -0.0161 & 0.1515 & -0.0458 & -0.0025 & -0.0251 \\
\hline 2013m6 & 11,500 & 0.0726 & 0.1078 & 0.0112 & 0.0803 & 0.1130 & 0.1985 & -0.0392 & 0.1035 & -0.0308 & 0.0043 & -0.0232 \\
\hline 2013m7 & 410 & 0.0815 & 0.1592 & 0.0044 & 0.0802 & 0.1343 & 0.2489 & -0.0584 & 0.1260 & -0.0445 & 0.0333 & -0.0458 \\
\hline 2013m8 & 1,038 & 0.0597 & 0.0985 & 0.0029 & 0.0605 & 0.0958 & 0.1856 & -0.0682 & 0.0841 & -0.0243 & 0.0145 & -0.0235 \\
\hline 2013m9 & 2,046 & 0.0665 & 0.0958 & 0.0025 & 0.0674 & 0.1100 & 0.1982 & -0.0455 & 0.1007 & -0.0343 & -0.0050 & -0.0334 \\
\hline $2013 m 10$ & 203 & 0.0790 & 0.1305 & 0.0047 & 0.0734 & 0.1339 & 0.2638 & -0.0360 & 0.1439 & -0.0649 & -0.0134 & -0.0705 \\
\hline 2013m11 & 55 & 0.0731 & 0.1404 & 0.0015 & 0.0626 & 0.1292 & 0.2874 & -0.0567 & 0.1498 & -0.0767 & -0.0094 & -0.0871 \\
\hline 2013m12 & 11,054 & 0.0897 & 0.1541 & 0.0025 & 0.0957 & 0.1490 & 0.3047 & -0.0690 & 0.1552 & -0.0655 & -0.0011 & -0.0595 \\
\hline 2014m1 & 50 & 0.0353 & 0.0505 & 0.0004 & 0.0270 & 0.0896 & 0.2006 & -0.0212 & 0.1119 & -0.0765 & -0.0614 & -0.0849 \\
\hline 2014m2 & 76 & 0.0771 & 0.1177 & 0.0007 & 0.0829 & 0.1303 & 0.2456 & -0.0282 & 0.1361 & -0.0590 & -0.0184 & -0.0532 \\
\hline 2014m3 & 601 & 0.0717 & 0.1032 & 0.0057 & 0.0698 & 0.1112 & 0.2086 & -0.0357 & 0.1109 & -0.0392 & -0.0077 & -0.0411 \\
\hline 2014m4 & 291 & 0.0653 & 0.1566 & 0.0028 & 0.0658 & 0.0991 & 0.1928 & -0.0443 & 0.0979 & -0.0326 & 0.0587 & -0.0321 \\
\hline 2014m5 & 772 & 0.0809 & 0.1212 & 0.0369 & 0.0945 & 0.1187 & 0.1941 & 0.0053 & 0.1186 & -0.0378 & 0.0026 & -0.0241 \\
\hline 2014m6 & 11,931 & 0.1017 & 0.1556 & 0.0250 & 0.1211 & 0.1535 & 0.2463 & 0.0338 & 0.1613 & -0.0595 & -0.0057 & -0.0402 \\
\hline 2014m7 & 426 & 0.0666 & 0.0211 & 0.0055 & 0.0744 & 0.1054 & 0.1595 & 0.0383 & 0.1110 & -0.0445 & -0.0899 & -0.0366 \\
\hline 2014m8 & 1,061 & 0.0946 & 0.1518 & 0.0052 & 0.1123 & 0.1462 & 0.2380 & 0.0716 & 0.1714 & -0.0768 & -0.0196 & -0.0592 \\
\hline 2014m9 & 2,079 & 0.0567 & 0.0800 & 0.0061 & 0.0606 & 0.0892 & 0.1633 & 0.0416 & 0.1146 & -0.0579 & -0.0346 & -0.0540 \\
\hline $2014 \mathrm{~m} 10$ & 212 & 0.0524 & 0.0705 & 0.0149 & 0.0574 & 0.0786 & 0.1424 & 0.0480 & 0.1046 & -0.0522 & -0.0341 & -0.0472 \\
\hline $2014 \mathrm{~m} 11$ & 54 & 0.0589 & 0.0722 & 0.0024 & 0.0534 & 0.0751 & 0.1381 & 0.0760 & 0.1133 & -0.0544 & -0.0411 & -0.0599 \\
\hline $2014 \mathrm{~m} 12$ & 11,414 & 0.0325 & 0.0418 & 0.0003 & 0.0296 & 0.0525 & 0.1051 & 0.1015 & 0.1037 & -0.0712 & -0.0619 & -0.0741 \\
\hline 2015m1 & 52 & 0.0337 & 0.0366 & 0.0021 & 0.0236 & 0.0558 & 0.1083 & 0.1087 & 0.1085 & -0.0748 & -0.0719 & -0.0849 \\
\hline 2015m2 & 83 & 0.0498 & 0.0567 & 0.0026 & 0.0478 & 0.0716 & 0.1187 & 0.0762 & 0.1017 & -0.0519 & -0.0450 & -0.0540 \\
\hline 2015m3 & 623 & 0.0398 & 0.0491 & 0.0014 & 0.0362 & 0.0564 & 0.1021 & 0.0892 & 0.0969 & -0.0572 & -0.0478 & -0.0607 \\
\hline 2015m4 & 293 & 0.0386 & 0.0986 & 0.0012 & 0.0394 & 0.0640 & 0.1098 & 0.0716 & 0.0945 & -0.0560 & 0.0041 & -0.0551 \\
\hline
\end{tabular}




\begin{tabular}{|c|c|c|c|c|c|c|c|c|c|c|c|c|}
\hline 2015m5 & 772 & 0.0363 & 0.0545 & 0.0109 & 0.0356 & 0.0546 & 0.0991 & 0.0475 & 0.0784 & -0.0421 & -0.0239 & -0.0429 \\
\hline 2015m6 & 12,186 & 0.0129 & 0.0416 & 0.0000 & 0.0072 & 0.0255 & 0.0486 & 0.0307 & 0.0414 & -0.0286 & 0.0001 & -0.0342 \\
\hline 2015m7 & 439 & 0.0222 & 0.0333 & 0.0000 & 0.0166 & 0.0420 & 0.0835 & 0.0465 & 0.0687 & -0.0465 & -0.0354 & -0.0521 \\
\hline 2015m8 & 1,068 & -0.0157 & 0.0269 & -0.0354 & -0.0116 & 0.0000 & -0.0209 & 0.0260 & -0.0021 & -0.0135 & 0.0290 & -0.0094 \\
\hline 2015m9 & 2,117 & -0.0187 & -0.0267 & -0.0400 & -0.0150 & 0.0000 & -0.0296 & 0.0555 & 0.0044 & -0.0231 & -0.0311 & -0.0194 \\
\hline $2015 \mathrm{~m} 10$ & 206 & 0.0041 & 0.0335 & -0.0050 & 0.0001 & 0.0182 & 0.0206 & 0.0340 & 0.0260 & -0.0218 & 0.0075 & -0.0259 \\
\hline $2015 \mathrm{~m} 11$ & 48 & 0.0118 & 0.0139 & -0.0052 & 0.0005 & 0.0135 & 0.0019 & 0.0159 & 0.0075 & 0.0043 & 0.0064 & -0.0071 \\
\hline $2015 \mathrm{~m} 12$ & 11,582 & -0.0108 & -0.0008 & -0.0261 & -0.0059 & 0.0000 & -0.0168 & 0.0107 & -0.0058 & -0.0049 & 0.0050 & -0.0001 \\
\hline 2016m1 & 49 & -0.0286 & -0.0287 & -0.0499 & -0.0176 & 0.0003 & -0.0470 & -0.0016 & -0.0289 & 0.0003 & 0.0001 & 0.0113 \\
\hline $2016 \mathrm{~m} 2$ & 82 & -0.0265 & -0.0861 & -0.0756 & -0.0272 & 0.0005 & -0.0970 & 0.0412 & -0.0417 & 0.0152 & -0.0444 & 0.0145 \\
\hline 2016m3 & 607 & -0.0134 & -0.0197 & -0.0357 & -0.0126 & 0.0000 & -0.0231 & 0.0312 & -0.0014 & -0.0120 & -0.0183 & -0.0112 \\
\hline $2016 \mathrm{~m} 4$ & 276 & -0.0123 & -0.0613 & -0.0359 & -0.0063 & 0.0010 & -0.0201 & 0.0349 & 0.0019 & -0.0142 & -0.0632 & -0.0082 \\
\hline 2016m5 & 755 & -0.0145 & -0.0338 & -0.0365 & -0.0160 & 0.0001 & -0.0162 & 0.0401 & 0.0063 & -0.0208 & -0.0401 & -0.0223 \\
\hline 2016m6 & 12,176 & -0.0063 & -0.0174 & -0.0237 & -0.0013 & 0.0060 & 0.0062 & 0.0949 & 0.0417 & -0.0480 & -0.0591 & -0.0429 \\
\hline 2016m7 & 440 & 0.0149 & -0.0422 & -0.0005 & 0.0064 & 0.0247 & 0.0327 & 0.0821 & 0.0525 & -0.0375 & -0.0947 & -0.0461 \\
\hline 2016m8 & 1,065 & 0.0370 & 0.0358 & 0.0003 & 0.0379 & 0.0632 & 0.1017 & 0.0748 & 0.0910 & -0.0539 & -0.0552 & -0.0531 \\
\hline 2016m9 & 2,106 & 0.0555 & 0.0694 & 0.0073 & 0.0627 & 0.0887 & 0.1437 & 0.0546 & 0.1080 & -0.0526 & -0.0386 & -0.0454 \\
\hline $2016 \mathrm{~m} 10$ & 208 & 0.0237 & 0.0575 & 0.0015 & 0.0222 & 0.0381 & 0.0419 & 0.0460 & 0.0435 & -0.0198 & 0.0139 & -0.0214 \\
\hline $2016 \mathrm{~m} 11$ & 48 & 0.0283 & 0.0237 & 0.0000 & 0.0308 & 0.0564 & 0.0814 & 0.0068 & 0.0516 & -0.0232 & -0.0279 & -0.0208 \\
\hline 2016m12 & 11,638 & 0.0439 & 0.0533 & 0.0025 & 0.0462 & 0.0697 & 0.1269 & 0.0070 & 0.0789 & -0.0350 & -0.0256 & -0.0328 \\
\hline 2017m1 & 49 & 0.0731 & 0.0789 & 0.0026 & 0.0713 & 0.1123 & 0.2216 & -0.0199 & 0.1250 & -0.0519 & -0.0461 & -0.0537 \\
\hline 2017m2 & 80 & 0.0754 & 0.1254 & 0.0019 & 0.0737 & 0.1358 & 0.2606 & -0.0289 & 0.1448 & -0.0694 & -0.0194 & -0.0711 \\
\hline 2017m3 & 597 & 0.0656 & 0.0870 & 0.0072 & 0.0770 & 0.1078 & 0.1801 & -0.0251 & 0.0980 & -0.0324 & -0.0110 & -0.0210 \\
\hline $2017 \mathrm{~m} 4$ & 272 & 0.0673 & 0.1239 & 0.0126 & 0.0750 & 0.1047 & 0.1775 & -0.0099 & 0.1025 & -0.0353 & 0.0214 & -0.0275 \\
\hline 2017m5 & 742 & 0.0828 & 0.1163 & 0.0480 & 0.0956 & 0.1161 & 0.1717 & -0.0034 & 0.1017 & -0.0189 & 0.0146 & -0.0061 \\
\hline 2017m6 & 12,157 & 0.0798 & 0.1161 & 0.0284 & 0.0929 & 0.1193 & 0.1791 & -0.0368 & 0.0928 & -0.0130 & 0.0234 & 0.0002 \\
\hline 2017m7 & 433 & 0.0643 & 0.0371 & 0.0117 & 0.0768 & 0.1054 & 0.1582 & -0.0399 & 0.0789 & -0.0146 & -0.0418 & -0.0022 \\
\hline 2017m8 & 1,045 & 0.0689 & 0.1110 & 0.0107 & 0.0769 & 0.1055 & 0.1568 & -0.0157 & 0.0878 & -0.0189 & 0.0232 & -0.0109 \\
\hline 2017m9 & 2,076 & 0.0768 & 0.1107 & 0.0212 & 0.0878 & 0.1165 & 0.1807 & -0.0313 & 0.0959 & -0.0191 & 0.0148 & -0.0081 \\
\hline $2017 \mathrm{~m} 10$ & 206 & 0.0885 & 0.1540 & 0.0216 & 0.1110 & 0.1441 & 0.2300 & -0.0171 & 0.1312 & -0.0427 & 0.0229 & -0.0202 \\
\hline $2017 \mathrm{~m} 11$ & 47 & 0.0842 & 0.0960 & 0.0000 & 0.1007 & 0.1470 & 0.2145 & 0.0221 & 0.1375 & -0.0533 & -0.0415 & -0.0368 \\
\hline
\end{tabular}




$\begin{array}{lcccccccccccc}2017 \mathrm{~m} 12 & 11,562 & 0.0934 & 0.1563 & 0.0163 & 0.1110 & 0.1446 & 0.2066 & 0.0280 & 0.1352 & -0.0418 & 0.0211 & -0.0241 \\ 2018 \mathrm{~m} 1 & 45 & 0.0977 & 0.1177 & 0.0016 & 0.1119 & 0.1425 & 0.2402 & 0.0016 & 0.1447 & -0.0470 & -0.0270 & -0.0328 \\ 2018 \mathrm{~m} 2 & 77 & 0.0626 & 0.0875 & 0.0009 & 0.0645 & 0.1012 & 0.1535 & -0.0187 & 0.0846 & -0.0220 & 0.0029 & -0.0201 \\ 2018 \mathrm{~m} 3 & 587 & 0.0608 & 0.0923 & 0.0089 & 0.0715 & 0.0967 & 0.1299 & -0.0086 & 0.0745 & -0.0137 & 0.0177 & -0.0030 \\ 2018 \mathrm{~m} 4 & 263 & 0.0490 & 0.0685 & 0.0019 & 0.0553 & 0.0821 & 0.1245 & -0.0346 & 0.0609 & -0.0119 & 0.0076 & -0.0055 \\ 2018 \mathrm{~m} 5 & 748 & 0.0618 & 0.0903 & 0.0363 & 0.0696 & 0.0854 & 0.1432 & -0.0329 & 0.0728 & -0.0110 & 0.0176 & -0.0031 \\ 2018 \mathrm{~m} 6 & 11,889 & 0.0521 & 0.0907 & 0.0192 & 0.0584 & 0.0774 & 0.1386 & -0.0295 & 0.0713 & -0.0192 & 0.0194 & -0.0130 \\ 2018 \mathrm{~m} 7 & 417 & 0.0512 & 0.0133 & 0.0104 & 0.0567 & 0.0794 & 0.1511 & -0.0344 & 0.0769 & -0.0257 & -0.0637 & -0.0202 \\ 2018 \mathrm{~m} 8 & 1,020 & 0.0591 & 0.0846 & 0.0107 & 0.0610 & 0.0876 & 0.1840 & -0.0411 & 0.0940 & -0.0348 & -0.0094 & -0.0329 \\ 2018 \mathrm{~m} 9 & 2,051 & 0.0470 & 0.0671 & 0.0113 & 0.0487 & 0.0713 & 0.1571 & -0.0388 & 0.0787 & -0.0317 & -0.0116 & -0.0300 \\ 2018 \mathrm{~m} 10 & 199 & 0.0119 & 0.0135 & -0.0035 & 0.0017 & 0.0210 & 0.0512 & -0.0419 & 0.0139 & -0.0021 & -0.0005 & -0.0122 \\ 2018 \mathrm{~m} 11 & 49 & 0.0002 & 0.0105 & -0.0108 & 0.0000 & 0.0138 & 0.0422 & -0.0251 & 0.0153 & -0.0151 & -0.0048 & -0.0153 \\ 2018 \mathrm{~m} 12 & 10,693 & -0.0347 & -0.0030 & -0.0653 & -0.0410 & 0.0000 & -0.0628 & 0.0004 & -0.0375 & 0.0028 & 0.0345 & -0.0035 \\ \text { Full } & & & & & & & & & & & & \\ \text { Sample } & 265,548 & 0.0444 & 0.0601 & 0.0000 & 0.0257 & 0.0955 & 0.1213 & 0.0339 & 0.0864 & -0.0420 & -0.0172 & -0.0392\end{array}$

